Dr. Ibrahim Abd Elnabi ISSA

\title{
Traduction des référents culturels dans le roman « le voleur et les chiens » vers le français
}

\author{
Dr. Ibrahim Abd Elnabi ISSA \\ Maître de Conférences \\ Faculté des lettres \\ Université de Kafr El-Sheikh
}

Traduire les textes contenant des référents culturels n'est pas une tâche facile. Le traducteur doit être biculturel. Il doit connaître la culture de la langue de départ et celle d'arrivée. Son rôle ne se contente pas de transférer les mots et les phrases d'une langue à une autre. Cette étude fait le point sur la manière par laquelle le traducteur traduit le roman intitulé : «le voleur et le chien » de Naguib Mahfouz contenant des référents culturels: des noms propres, des toponymes, des nourritures et des boissons, des expressions idiomatiques, des proverbes,etc. Cette recherche essaie de répondre à cette question : Le traducteur est-il fidèle ou non au sens lors de la traduction?

Mots-clés : référents culturels- traduction - culture- approches de la traduction -fidélité au sens. 


\section{ترجمة المرجعيات الثقافية في رواية "اللص والكلاب" إلي اللغة الفرنسية}

\section{ملنـص}

ترجمة النصوص الأدبية التي تحتوي علي مرجعيات ثقافية ليست بالمهمة السهلة .لذا يجب أن يكون المترجم ذو ثقافة ازدواجية. وأن يكون علي دراية تامة بثقافة لغة المصدر ولغة الهدف. وأن لا يقتصر دوره علي نقل الكلمات والجمل من لغة إلي لغة أخري. هذه الدراسة تركز عي كيفية تعامل المترجم مع رواية "اللص والكلاب" للكاتب نجيب محفوظ و التي تحتوي علي مرجعيات ثقافية : أسماء العلم وأسماء الأماكن ومأكولات ومشروبات وملابس وتعبيرات اصطلاحية وحكم وأمثال...الخ. هذا البحث يحاول الإجابة على السؤال التالي : "هل المترجم مخلص للمعني خلال عملية الترجمة أم لا ؟" الكلمات المفتاحية : المرجعيات الثقافية- الترجمة-الثقافة- نظريات الترجمة - الإخلاص •لمعني 
Dr. Ibrahim Abd Elnabi ISSA

\title{
Traduction des référents culturels dans le roman « le voleur et les chiens » vers le français
}

\author{
Dr. Ibrahim Abd Elnabi ISSA \\ Maître de Conférences \\ Faculté des lettres \\ Université de Kafr El-Sheikh
}

\section{1-Introduction}

Par la traduction, on facilite la communication entre les peuples et les rapproche. Elle fait passer les connaissances culturelles d'une langue à une autre. "Le facteur culturel joue un rôle très important dans le processus des transferts textuels. Il intéresse les traducteurs qui se sentent obligés à recourir à intégrer à la théorie de la traduction "la perspective extralinguistique ou la para-linguistique ». ${ }^{l}$

La langue est indissociable de sa culture. Le traducteur ne s'intéresse pas seulement aux mots qu'il veut traduire, mais aussi à leur dimension culturelle. La traduction peut être définie comme le transfert d'un texte d'une langue à une autre langue. Cette définition ne doit pas négliger la dimension culturelle de deux langues: langue de départ (L1)et langue d'arrivée(L2). La culture fait irruption dans les composantes de la langue: lexique, morphologique, syntaxique. Sans cette dimension culturelle, la traduction ne saurait être authentique, ni efficace. Traduire une langue, c'est entrer dans une culture autre que la sienne. Le traducteur est en perplexité. Il veut être fidèle aux traits culturels du texte originel. Dans ce cas, sa traduction gagne en authenticité mais elle perd cependant en netteté

1. LADMIRAL, Jean René, Traduire, Théorèmes pour la traduction, coll.«.Tel», Paris, Gallimard, 1994, p.18
2018 العدد الرابع والعشرون (الجزء الثالث)
()
مجلة كلية التربية- جامعة عين شمس 119 
et en intelligibilité pour un lecteur ignorant la culture de l'auteur. Si le traducteur utilise un des procédés de traduction comme l'adaptation, l'équivalence, la modulation, la transposition culturelle, sa traduction gagne en accessibilité mais déforme et altère des passages entiers de l'oeuvre. Le traducteur affronte un défi quand il traite des textes ayant des tournures complexes, des expressions figées, des noms propres qui amènent à effectuer une équivalence ou une adaptation.

Dans cette recherche, nous traiterons certains aspects spécifiques de la traduction d'un des romans de Naguib Mahfouz. Nous mettrons en relief les approches théoriques de traduction que le traducteur a suivies pour traduire les référents culturels dans le roman. Le but de cette étude est d'analyser comment le traducteur de «Le voleur et les chiens » a traduit le facteur culturel et d'examiner ses solutions et ses stratégies. Nous avons examiné plus de 80 exemples. Nous avons classé les mots culturels en 10 taxinomies:les noms propres, les toponymes, les aliments, les boissons, les vêtements, les interjections, les expressions idiomatiques, les coutumes, les fêtes et les proverbes. Nous avons choisi ces éléments qui sont difficiles à traduire. Nous les avons comparés aux autres éléments français.

Pour effectuer notre corpus concernant la traduction des référents culturels, nous avons choisi le roman «Le voleur et les chiens », de l'auteur Naguib Mahfouz, traduit par Khaled Osmane. Ce roman est publié en arabe en 1961 et traduit en français par Khaled Osmane en 1996. Il contient 166 pages. Pour nous, il contient des mots référentiels concernant notre travail. De plus, les œuvres de Naguib Mahfouz se caractérisent par l'empreinte populaire. Il met en évidence les bidonvilles, les quartiers populaires,etc. C'est pourquoi, ses écritures sont considérées comme le miroir de la culture égyptienne comme en témoignent 
Dr. Ibrahim Abd Elnabi ISSA

d'autres œuvres comme La Trilogie du Caire : Volume I : Bayn alQasrayn, roman 1956 (trad. française Impasse des deux palais, 1987)Volume II : Qasr al-Chawq, roman 1957 (trad. française $\underline{L} \boldsymbol{e}$ Palais du désir, 1987) Volume III : Al-Sukkariyya, roman $\underline{1957}$ (trad. française $\underline{\text { Le Jardin du passé }}$, 1989).

À la base de traduction des référents cultures des textes littéraires, nous allons suivre les procédés de Vinay et Darbelnet qui sont : le calque, l'adaptation, la transposition, la modulation, l'équivalence, l'emprunt et la traduction littéral.

\section{2- Approche de Vinay et Darbelnet}

Bien que l'étude de Vinay et Darbelnet se fonde essentiellement sur la comparaison entre le français et l'anglais à travers le style d'expression de chacun de ces deux langues, nous trouvons des éléments de leur analyse qui s'appliquent à la comparaison entre les autres langues.

Les procédés de Vinay et Darbelnet décrivent minutieusement les changements qui se passent dans le texte pendant le processus de la traduction. Grâce à ces procédés, le traducteur les applique pour obtenir une grande utilité dans le domaine de la traduction. Ils sont :

\section{2-1-L'emprunt}

C'est l'aspect le plus simple. Par l'emprunt lexical, le traducteur utilise en langue d'arrivée le terme de la langue de

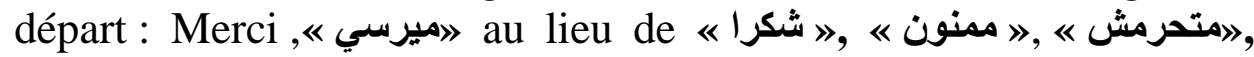
《ربنا يخليكا mot ou une telle expression sans modification de la langue de départ dans la langue d'arrivée. Il utilise le plus souvent l'emprunt quand le mot n'existe pas dans la culture de la langue d'arrivée. Son rôle réside dans la transcription du mot de la langue source selon l'usage de la langue cible. Par cette technique, le vocabulaire de la langue-cible s'enrichit. Prenant l'exemple des mots arabes comme: 
Traduction des référents culturels dans

le roman « le voleur et les chiens » vers le français

Omdeh(العمدة), Bastrma(بسطرمة), Mulkhaya *2 (ملوخية), que l'on ne retrouve pas en français.

\section{2-2-Le calque}

Le calque consiste à utiliser l'emprunt d'un syntagme de la langue de départ avec traduction littérale de ses composants : (ناطحة (سحاب est traduit par «gratte-ciel » qui est à son tour traduit de l'anglais «skyscraper ». Le traducteur emprunte à la langue étrangère le mot en traduisant littéralement ses composants : (هنوف) est traduit par (lune de miel) et (حقوق المؤلف) par(droits d'auteur.)

\section{2-3-La traduction littérale}

Ce procédé est poursuivi quand le traducteur traduit deux langues ayant des propriétés culturelles et génétiques proches comme le français et l'anglais. "La traduction littérale ou mot à mot désigne le passage de LD à LA aboutissant à un texte à la fois correct et idiomatique sans que le traducteur ait eu à se soucier d'autre chose que des servitudes linguistique: I left my spectacles on the table downstairs :j'ai laissé mes lunettes sur la table en bas. ${ }^{3}$ Prenons comme exemple ces deux phrases de deux langues n'ayant pas de même origine ni de même culture. :

$2 *$ - Mulkhaya : ici, nous parlons d'un repas ou une recette. Mais, il y a la plante qui consiste à faire ce repas. Cela signifie en français "corète potagère $"$

*La char' (arabe : الثَّرَّع) représente dans l'Islam diverses normes et règles doctrinales, sociales, cultuelles, et relationnelles édictées par la «Révélation».

${ }^{3}$-VINAY, J.-P. et DARBELNET, J., Stylistique comparée du français et de l'anglais, Paris, Didier, 1967, p. 48
2018
العدد الرابع والعشرون (الجزء الثالث)
()
مجلة كلية التربية- جامعة عين شمس122 
Traduction des référents culturels dans

le roman « le voleur et les chiens » vers le français

La phrase arabe qui contient (préposition+nom+complément du nom) est traduite par une phrase contenant (adverbe de temps +nom+ verbe+coi). Le traducteur recourt à la transposition qui consiste à traduire un mot par un mot appartenant à une autre catégorie grammaticale comme en témoigne l'exemple susmentionné. Ainsi, le traducteur utilise la transposition dans la phrase (Au moment où le muezzin appelle à la prière de l'aube) au lieu de (Lors de l'appel à la prière de l'aube.) Considérons aussi cet exemple :

" وها أنت تخرج من السجن Oui, te voilà hors de prison avec une

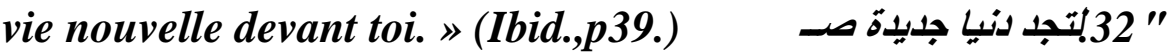

Le traducteur utilise ici deux procédés à savoir l'adaptation et la transposition : l'adaptation parce qu'il remplace un monde par une vie pour traduire (un monde nouvel) qui est remplacé par (une vie nouvelle) et la transposition parce qu'il modifie la structure de la phrase en remplaçant «tu sors de la prison » par (te voilà hors de prison.) Nous trouvons aussi un autre exemple dans notre corpus :

" جرت مشيتته أن نلقاه هكذ/."صد Dieu a voulu que je Le rencontre de cette façon. »(Ibid.,p.25.)

Le traducteur a ajouté le nom Dieu au lieu (adjectif possessif + nom). Autrement dit, Il remplace (son destin nécessite) par (Dieu a voulu). Le traducteur emploie ici l'adaptation.

\section{2-6-L'équivalence}

Opposé à l'emprunt, c'est l'aspect le plus difficile. Le traducteur l'utilise quand il ne peut traduire mot à mot les mots car les deux langues ne possèdent pas un code commun. Ce procédé est possible dans les proverbes, les collocations, les expressions idiomatiques, etc. Considérons ces exemples :

في المشمش= = When pigs fly= Quand les poules auront des dents مستحيل

-À la saint Glinglin = في المشمش 
-Avoir un poil dans la main= كسول

\section{2-7-L'adaptation}

L'adaptation : substituer une autre réalité culturelle à celle de la langue source. "L'expression arabe [atlagta sadri] (ثلجت صدري )fut traduite en français comme suit: tu m'as réchauffé le coeur or que le verbe [atlaga] est le contraire du verbe réchauffer qui veut dire: tu m'as rafraîchi par cette nouvelle. On remarque ici l'influence culturelle et même géographique et climatique.(...)Il devait ressortir de ce qui précède que toute traduction est par force adaptation. Il a été question plus haut à ce propos de passage d'une "langue-culture » à une autre.» ${ }^{6}$

L'adaptation est donc un procédé qu'on utilise quand la situation à laquelle on se réfère n'existe pas dans la langue d'arrivée, et doit être créée par rapport à une autre situation, que l'on juge équivalente. Par exemple, "LD "he kissed his daughter on the mouth", mais LA "il serra tendrement sa fille dans ses bras". À travers l'exemple précédent, on peut citer le fait pour un père anglais d'embrasser sa fille sur la bouche comme une donnée culturelle qui ne passerait pas telle quelle dans le texte français». ${ }^{7}$

L'adaptation substitue une autre réalité culturelle à celle de la langue source lorsque le lecteur étranger risque de ne pas reconnaître la référence. Le traducteur a recours à l'adaptation dans:

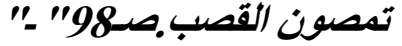

-«en train de mâchonner de la canne à sucre.» (MAHFOUZ,N.,p.119.)

Il remplace le verbe (sucent : تمصون) par (mâchent : تمضنغون). Il en va de même dans cet exemple :

6- MOUSSAOUI, Yamina Leila, l'influence culturelle sur la traduction de la poésie populaire : Traduire une langue ou un dialecte ? Université de Tlemcen No.23, 2014, pp.7-8. Cet article est disponible sur le site http://revue.ummto. dz/index.php/pla/ article /view/ 10 (Consulté le 10-32018)

7- VINAY, J.-P. et DARBELNET, J., Op. cit., p.52
2018
العدد الرابع والعشرون (الجزء الثالث)
()
مجلة كلية التربية- جامعة عين شمس 125 
Traduction des référents culturels dans

le roman « le voleur et les chiens » vers le français

وان يمتلك عليش تعب عمري كله بلعبة الكلاب ؟"-"

«-Et qu'Aliche ait réussi par une manoeuvre scélérate à me spolier des fruits d'une vie d'efforts?"

Le traducteur traduit (بلعبة الكلاب) qui signifie mot à mot "grâce au jeu de chiens" par " par une manoeuvre scélérate." Il a fait attention au facteur culturel de l'expression de la langue source que le récepteur ne comprendra pas.

Parmi les cas où le traducteur préfère l'adaptation, le mot est remplacé par la phrase «Est-elle avec quelqu'un?» L'héroïne « Nour » était prostituée. Le héros lui demande si elle est avec quelqu'un? Si le traducteur emploie le mot «pêcher» pour les poissons ou « chasser » pour les animaux, il y aura une confusion.

Le traducteur se voit ainsi obligé de recourir à l'adaptation. En ce qui concerne les couleurs, les Égyptiens utilisent le mot «حيني 》 qui fait référence à une nourriture répandue dans la société égyptienne et composée de sésames(طحينة). Nous trouvons que l'auteur emploie dans son roman cette couleur (قونص طحيني.73) que le traducteur traduit par (une chemise beige.) (MAHFOUZ,N.,p.88.) De même, le traducteur recourt aussi à l'adaptation dans ( تعدلون لههذا qui est traduit par (Vous avez retourné ce jour mille fois dans votre tête.) (Ibid.,p.7.) L'approche de Vinay et Darbelnet n'est pas exhaustive. Il y a d'autres procèdes de traduction.

\section{3-Autres procédés de traduction}

Pour les problèmes de traduction de référents culturels, les traducteurs ont recours aux différentes stratégies de traduction. Nous mettons en évidence un aperçu sur les autres approches de traduction.

\section{3-1-Approche de Georges Mounin}

G..Mounin a distingué deux façons de traduire (d'être fidèle) :

«Les verres transparents : Le traducteur adoptant cette méthode se doit d'effacer l'originalité de la langue étrangère (fidélité à la langue 


\section{Dr. Ibrahim Abd Elnabi ISSA}

d'arrivée.) Les verres colorés : sont les traductions mot à mot. Tout en comprenant la langue, le lecteur «sent» les différences temporelles, civilisationnelles et culturelles que la traduction véhicule (fidélité à la langue de départ). ${ }^{8}$

Mounin ne néglige pas la réalité linguistique de la traduction, il prouve qu'il y a des aspects «non-linguistiques» et «extralinguistiques » existant dans la traduction. G. Mounin affirme: " $L a$ traduction, comme l'architecture ou la médecine (ou tant d'autres activités humaines ayant pour l'objet l'homme) est, ou peut être, ou doit être à la fois une science et un art: un art sous - tendu par la science. C'est la linguistique elle - même qui nous enseigne le plus clairement que les opérations de traduction comportent à la fois des problèmes linguistiques et des problèmes non - linguistiques."

\section{3-2-Approche de Lederer et Seleskovitch}

C'est la théorie du sens, on l'appelle aussi la théorie de la traduction interprétative. Selon cette théorie, le traducteur traduit le message et le sens, il ne travaille pas sur les mots.

«Pour D. Seleskovitch, il s'agit en traduction de faire passer le sens d'un message en produisant le même effet chez le destinataire. A partir de cette définition on ne peut définir la fidélité que comme une fidélité au sens.» ${ }^{10}$

Dans cette théorie, la traduction doit passer par trois phases (la compréhension, la déverbalisation et la réexpression.) Le traducteur, selon Lederer, joue son rôle en faisant une irruption pour traiter les textes aux référents culturels. Il a recours à une

${ }^{8}$-Cet article est disponible sur le site : http://translationjournal. net/journal/ 18fidelite. htm (Consulté le 1-02-2018)

9-BALLARD, M.,La traduction de I' anglais au français, Paris, Ed.Nathan,1998, p.6

10. Ibid, p.11

2018 العدد الرابع والعشرون (الجزء الثالث)

مجلة كلية التربية- جامعة عين شمس127 
Traduction des référents culturels dans

le roman «le voleur et les chiens » vers le français

explication en bas de page pour faire comprendre le lecteur le contenu ou le sens culturel du texte. Seleskovitch et Lederer en ajoute : "Pour traduire, comprendre soi-même ne suffit pas, il faut faire comprendre (...)Traduire honnêtement, traduire fidèlement par contre c'est chercher à se faire comprendre, et se faire comprendre suppose trouver l'expression juste. " 11

\section{3-3-Approche de Nida}

D'après Nida, il y a deux types d'équivalence: l'une formelle, le traducteur et le récepteur s'intéressent seulement au message "Le traducteur qui adopte cette stratégie s'efforce de faire correspondre le plus précisément possible le message en langue cible aux éléments concrets de la langue source. Il s'agit d'une équivalence désignée aussi comme structurelle ou de «traduction glosse ", où le traducteur cherche à reproduire le plus littéralement possible la forme et le contenu de l'original. ${ }^{12}$ et l'autre, le récepteur cible ne s'intéresse pas au contenu culturel du contexte source. Il connaît seulement le contenu significatif du texte source. "ce type de traduction est basé sur le principe de l'équivalence d'effet, elle se veut rédigée de manière parfaitement naturelle et cherche à mettre en relation le récepteur avec des modes de comportement significatifs en contexte cible ; ceci est une traduction commode pour le récepteur qui n'est pas obligé de connaître les modèles culturels du contexte source pour comprendre le message. ${ }^{13}$

11_SELESKOVITCH, Danica et LEDERER, Marianne; Interpréter pour traduire, Paris, Didier érudition, 1984,p.31

12 - RAKOVÁ, Zuzana. La traduction équivalente, adéquate ou fonctionnellequelle doctrine traductologique pour le XXIe siècle?. Études romanes de Brno, 2013, 1: p.58

13 -Loc.cit

العدد الرابع والعشرون (الجزء الثالث) 2018

مجلة كلية التربية- جامعة عين شمس128 


\section{Dr. Ibrahim Abd Elnabi ISSA}

Après avoir présenté un aperçu général sur l'approche de Vinay et Darbelnet que nous utilisons en analysant notre corpus et les autres approches de traduction, passons maintenant à définir les référents culturels et la relation entre la culture et la traduction.

\section{4-Les référents culturels}

Quels sont les référents culturels qui posent problème lors d'une traduction? Plusieurs termes sont utilisés pour mettre en évidence les mots culturels. Michel Ballard les appelle "les référents

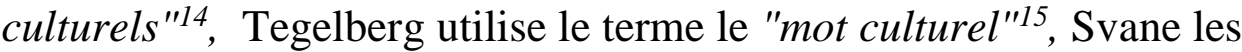
appelle"les expressions référentielles" ${ }^{\prime 16}$, il s'agit des phénomènes hors-textuels et des images culturelles. Nous avons choisi le terme utilisé par Michel Ballard. Ce terme désigne une culture matérielle différente(vêtements, nourritures, boissons, etc.), un événement socioculturel spécifique(rites, fêtes, système militaire, économique, etc.), des expressions figées et établies entre les membres de la même communauté. "Le problème est que la connaissance du

14_ BALLARD, M., " Le cultèreme en traduction : entre sens indice et écriture ". In : Eriksson O. (éd). Översättning och kultur, föredrag från ett symposium vid Växjö universitet 17-18 november 2006. Växjö : Växjö University Press, pp 19-40.2007, p.22. In: Sara Lindsten, Comment traduire la culture ? Etude sur la traduction des mots culturels dans la traduction d'un roman de Mons Kallentoft, Göteborgs universitet,2013, p.5

* Les culturèmes sont des unités culturellement marquées, de taille variable, indécomposables et qui sont normalement considérées comme des éléments difficilement intraduisibles

15. TEGELBERG, E., "Kvällstidning ", journal à sensation ? Le problème de la traduction en français des "mots culturels " suédois ", Moderna språk. no 2,2004, p.184

16- SVANE, B., " Comment traduire la réalité ? Étude de la traduction des expressions référentielles», 1998, p.93. In : Eriksson, O. (éd). Språk- och kulturkontraster, om översättning till och från franska. Åbo : Åbo Akademis förlag, pp. 93-118,

العدد الرابع والعشرون (الجزء الثالث) 2018

مجلة كلية التربية- جامعة عين شمس 129 
Traduction des référents culturels dans

le roman « le voleur et les chiens » vers le français

monde n'est pas la même chez les lecteurs du texte cible que chez le public du texte original et que souvent les 'signifiants' des culturèmes *spécifiques sont vides de sens pour ceux qui n'ont pas vécu les phénomènes désignés. ${ }^{17}$

Dans notre corpus, nous rencontrons plusieurs référents culturels propres à la société égyptienne comme : ابلع ريقك_شربات-) (حلقة ذكر posent problème lors d'une traduction. Mais nous nous demandons quelle est la définition de la culture en générale ?

\section{5- La culture}

La définition de la culture n'est pas une tâche facile. Selon Mounin, la culture est considérée comme «l'ensemble des activités et des institutions par où cette communauté se manifeste.» ${ }^{18} \mathrm{La}$ connaissance de la culture de la langue source permet d'identifier les situations communes à la culture de la langue cible et partant de rendre la traduction possible.

La culture n'est pas identique dans tous les pays. Au niveau des mots, des coutumes, des vêtements, etc., chaque pays a sa propre culture. Par exemple, en Égypte, il y a une fête qui n'existe pas en France et vice-versa. En Égypte, il y a " مولد: Mouled", une fête dans laquelle certains Égyptiens se réunissent autour de la tombe d'un cheikh. Ces phénomènes possèdent des mots ou des expressions déterminées difficiles que le traducteur ne peut facilement traduire. Par exemple, comment traduire en français un

${ }^{17}$-SVANE, Brynja, Culturèmes, références et les mots pour le dire - la traduction française de Jens Peter Jacobsen : 'Mogens', 2007, p.138. In : Eriksson, Olof (éd.). Översättning och kultur, föredrag från ett symposium vid, Växjö University Press, 2006, pp. 131-147.

${ }^{18}$-MOUNIN, Georges, les problèmes théoriques de la traduction, Paris, Gallimard, 1963, p. 233

العدد الرابع والعشرون (الجزء الثالث) 2018

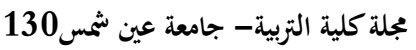




\section{Dr. Ibrahim Abd Elnabi ISSA}

phénomène de la culture égyptienne comme cham elnassim, la fête $\mathrm{du}$ printemps où les Égyptiens mangent Fesikh (les poissons salés).Comme ils partagent la même culture, les citoyens comprennent sans médiateur ces mots culturels.

Jean Sévry ${ }^{19}$ distingue quatre niveaux de la culture :

-un corpus d'habitudes, façons de se vêtir, se tenir à table, d'échanger des cadeaux et des politesses sociales, des salutations ; -une façon d'organiser le temps par les calendriers agraires, voire lunaires, de s'installer dans ce temps par une série de marquages indiquant les moments les plus importants de la vie; tels la naissance, le mariage, la mort et le travail du deuil, les funérailles ; -des systèmes de parente, la structuration du groupe en classes d'âge, une façon de situer l'autorité, de rendre justice, de gérer les pouvoirs politiques ;

-une façon d'occuper l'espace et les sols, de fabriquer des paysages et des habitats, d'organiser des architectures, tout un système de représentations du monde, une relation instaurée entre l'homme, la nature, le cosmos, l'ici et maintenant et l'au-delà, c'est-à-dire le sacré, qui s'est mis en place au gré de l'histoire.

Pour Christiane Nord qui observe "que la culture n'est aucunement un phénomène matériel; elle ne consiste pas en des objets, des personnes, des comportements, ni des émotions. Elle réside plutôt dans l'organisation de ces choses» ${ }^{20}$, la culture se divise en:

19-SÉVRY, Jean, Une fidélité impossible: traduire une œuvre africaine anglophone. Palimpsestes. Revue de traduction, 1998, 11: p.134 in Petronela Munteanu, Traduction et culture,université de suceava,2011 p.116

${ }^{20}$-NORD, Christiane, La traduction, une activité ciblée, Introduction aux approches fonctionnalistes, Artois Presses Université, 2008, p.37
العدد الرابع والعشرون (الجزء الثالث) 2018
()
مجلة كلية التربية- جامعة عين شمس 131 - مبر 
Traduction des référents culturels dans

le roman « le voleur et les chiens » vers le français

-Paraculture(les normes, les règles et les conventions valables pour toute une société) ;

-Diaculture (les normes, les règles et les conventions valables pour un groupe spécifique à l'intérieur de cette société, tels un club, une entreprise, une entité régionale) et enfin,

-Idioculture(la culture d'un individu pris isolement, par contraste avec les autres individus).

Nous pouvons prétendre que la culture est, dans une société, le miroir de tout ce qui suit : les mœurs, les coutumes, les rites, les fêtes, les vêtements, les repas, les jeux, les éthiques, les arts, la littérature, la connaissance, les expériences, le patrimoine artistique, littéraire et intellectuel,etc.

\section{6-Traduction et la culture}

Qu'est-ce que la traduction? La définition la plus simple et la plus claire est : "La traduction consiste à faire passer un message d'une langue de départ (langue source) dans une langue d'arrivée(langue cible). Le terme désigne à la fois l'activité et son produit: le message cible comme "traduction" d'un message source, ou « original. » ${ }^{21}$

La question de la traduction de la culture préoccupe les traductologues. Les uns acceptent l'idée de traduire les textes à contenu culturel. Les autres sont contre cette opinion. Selon Berman, " toute culture résiste à la traduction. ${ }^{22}$

21-DUBOIS ,Jean et al., Dictionnaire de linguistique, Larousse, Paris, 2002, p. 486

22-BERMAN, Antoine, L'épreuve de l'étranger, culture et traduction dans l'Allemagne romantique, Paris, collection les Essais $\left(n^{\circ} 226\right)$, Gallimard,1984, p.16 
Pour nous, le traducteur ne peut négliger la dimension culturelle du texte-source. Son rôle consiste à relier la culture de deux langues. S'il n'a pas cette compétence, sa traduction sera vaine et incompréhensible. Il ne peut exclure les éléments culturels : "Traduire, c'est établir un contact avec un ensemble d'autres contacts, connus ou inconnus par le traducteur, traduire c'est aussi travaillé sur la base des échanges culturels. . ${ }^{23}$ Le traducteur doit prendre en considération les éléments extralinguistiques du textesource comme l'affirme Katharina Reiss :« [...] rendre en langue cible les instructions intra linguistique du texte original sans tenir compte des déterminants extralinguistiques, c'est se condamner à n'émettre qu'un embryon de jugement. Car ce sont précisément ces déterminants extralinguistiques dont le rôle est décisif aussi bien pour la mise en forme langagière de l'original que pour la rédaction de la version cible qui permettent de dire si les équivalences proposées sont potentielles ou si elles sont optimales. ${ }^{24}$

Pour traduire les textes à contenu culturel, le traducteur se voit obligé d'opter le procédé le plus adapté pour transmettre la réalité de la culture donnée, sinon sa mission échouera. Il y a deux types de procédées de traduction. Le premier, c'est le procédé direct qui renferme l'emprunt, le calque et la traduction littérale. Le second, c'est le procédé indirect qui contient l'équivalence, l'adaptation, la modulation, la transposition. Le traducteur choisit un de ces procédés en fonction du public ciblé par la traduction, du domaine et $\mathrm{du}$ style du texte. Il se voit parfois obligé d'ajouter une explication en note de bas de page.

23_CORDONNIER, J.L, Traduction et culture, Paris, Hatier, 1995, p.11 24-TATILON, Claude et REISS Katharina, La critique des traductions, ses possibilités et ses limites, traduit de l'allemand par Catherine Bocquet, Cahier de l'Université d'Artois, 32/2002, Arras, Artois Presses Université, 2002,p.88 
Quand le traducteur traduit un texte, il ne s'agit pas seulement de suivre une technique linguistique, mais aussi de connaître la culture véhiculée par la langue comme en témoigne Eco Umberto qui confirme que "la traduction ne concerne pas seulement un passage entre deux langues, mais entre deux cultures, ou deux encyclopédies. Un traducteur tient compte des règles linguistiques, mais aussi d'éléments culturels, au sens le plus large du terme. ${ }^{25}$

Étant biculturel et bilingue, le traducteur peut résoudre le problème des obstacles culturels, il se doit comprendre les cultures de la langue de départ et d'arrivée et son ethnographie dont la traduction littérale mène à la banalité. Il doit être comme artiste. «La traduction comme l'architecture ou la médecine est, ou peut être, ou doit être à la fois une science et un art : un art sous-entendu par une science». ${ }^{26}$

La langue se caractérise par ses règles grammaticales et ses aspects sémantiques et pragmatiques qui ne se traduisent pas facilement et spontanément dans une autre langue. Le traducteur se met à faire des adaptations et des modifications pour que le texte de L2 soit convenable et compréhensible, ce qui implique que le traducteur ne joue que le rôle du transmetteur du message, mais aussi celui de l'émetteur. ${ }^{27}$

*-Na'eeman : est une expression du parler égyptien qui signifie« Que Dieu te donne du bien ou Que Dieu te bénisse ! "

${ }^{25}$-ECO, Umberto, Dire presque la même chose, Expériences de traduction, Paris, Grasset, 2007, p. 190

${ }^{26}$-MOUNIN, Georges, Linguistique et traduction, Belguim, Dessart \& Mardaga, 1976, p.111

27- Cf., PERGNIER, M., Les fondements sociolinguistiques de la traduction, Presses Universitaires de Lille, 1978, p.59. 


\section{7-Fidélité au sens}

La question qui s'impose à ce propos: est-ce que le traducteur est fidèle ou infidèle au texte intégral en traduisant les référents culturels ? Imaginons qu'un homme sort de la coiffure, qu'est-ce que le coiffeur lui dit après la coupe des cheveux ? En Egypte, le coiffeur nous dit : «عيماً dont la translittération est «Na'eeman»*. Donc, comment le traducteur peut-il le traduire? «Parler de traduction, $[\ldots]$ c'est parler du mensonge et de la vérité, de la trahison et de la fidélité. $»^{28}$

Le traducteur doit être créateur car la traduction qui est sans créativité est un projet échoué. Il transmet le sens pour reproduire le même effet du texte de la langue de départ. Le traducteur se voit parfois obligé à supprimer des parties du texte de la langue de départ. Il supprime le plus souvent le mot culturel que le récepteur ne peut le comprendre. Tous ces procédés sont considérés comme infidélité au sens ou trahison. En citant l'expression italienne "Traduttore, traditore » qui signifie soit « Traduire, traître », soit « Traduire, c'est trahir ». On compare le traducteur à un traître car il ne peut respecter le texte de la langue de départ en traduisant un texte.

La fidélité ne signifie pas la traduction littérale qui peut aboutir à un contresens, mais elle fait référence à la littéralité du sens contextuel qui prend en considération la corrélation de la langue/culture pour parvenir à la compréhension exacte et à la

28-BERMAN, Antoine: "Au début était le traducteur ", TTR : traduction, terminologie, rédaction, 14.2, 2001 p. 17.in MEHNERT Sabine " "Traduire, c'est trahir" ? Pour une mise en question des notions de vérité, de fidélité et d'identité à partir de la traduction ", Trajectoires [En ligne], 9 |2015, mis en ligne le 15 décembre 2015, consulté le 08 novembre 2017. URL: http://trajectoires.revues.org/1649

العدد الرابع والعشرون (الجزء الثالث) 2018

مجلة كلية التربية- جامعة عين شمس135 
traduction fidèle. J.R. Ladlmiral, parlant de la fidélité déclare que " Toute théorie de la traduction est confrontée au vieux problème du MEME et de L'AUTRE : à strictement parler, le texte cible n'est pas le MEME que le texte original, mais il n'est pas tout à fait un AUTRE.» ${ }^{29}$

Nous nous demandons comment le traducteur traite les textes contenant des jeux de mots, des inventions esthétiques dont la traduction semble difficile. "Être fidèle en traduction ne se pose plus en termes de fidélité envers l'auteur ou envers le lecteur, en termes de respect pour le sens ou l'esthétique, sinon en termes pragmatiques: le texte original doit faire ce que le texte original fait. Octavio Paz (1981) affirme - et le démontre avec sa pratique de traduire - que le texte original jamais ne réapparaît (serait-il impossible) dans la langue d'arrivée, et pourtant, il y est présent toujours parce que "la traduction, sans le dire, le mentionne constamment ou le transforme dans un objet verbal qui, bien que distinct, le reproduit ». Alors, le point d'arrivée du bon traducteur "c'est un poème analogue, non plus identique, du poème original $\gg .{ }^{30}$

La fidélité au sens réside dans le respect de trois points :

- les propriétés linguistiques de deux langues : L1 et L2 ;

- les propriétés stylistiques du texte source au texte traduit ;

- les propriétés sociolinguistiques de deux langue : Langue de départ et langue d'arrivée.

29-LADMIRAL, Jean-René, Op.cit., p.16. Disponible sur le site: http:// translationjournal.net/ journal/ 18fidelite.htm (Consulté le 21-1-2017) 30_ Cet article est disponible sur le site : http://www.arches.ro/revue/no04/no4art07.htm (Consulté le 20-11-2017) 
Dr. Ibrahim Abd Elnabi ISSA

Nous sommes devant une infidélité formelle et fidélité sur le plan de signification. Étant fidèle au texte original, Le traducteur veut établir une certaine identité entre le texte-source et le texte-cible et réaliser l'équivalence de l'original et du texte traduit.

\section{8-Analyse du corpus}

Les difficultés que pose la traduction du roman «le voleur et les chiens » sont : les expressions idiomatiques, les proverbes, les noms propres, les toponymes, les nourritures, les boissons, les vestimentaires, les rues, les journaux. Dans les lignes suivantes, nous analysons en détail comment le traducteur a pu traduire le roman en transférant la dimension culturelle de cet œuvre littéraire.

\section{8-1-Les nom propres}

Les noms propres sont traduisibles ou intraduisibles? Les noms propres se caractérisent par leur intraduisibilité. Ils restent figés et invariables. Georges Moore affirmait que «tous les noms propres, quelque imprononçables qu'ils soient, doivent être rigidement respectés. ${ }^{31}$ Les linguistes n'en sont pas d'accord. Le premier parti comme George Moore et George Kleiber déclarent la traductibilité des noms propres et le deuxième parti comme Algeo et Delisle soutiennent leur non- traductibilité.

George Moore, pour qui «Tous les noms propres [...] doivent être rigoureusement respectés », ou encore Georges Kleiber (1981) pour qui, suivant sa théorie du nom propre comme prédicat

* La translittération est l'opération qui consiste à substituer à chaque graphème d'un système d'écriture un graphème ou un groupe de graphèmes d'un autre système, indépendamment de la prononciation. Elle dépend donc du système d'écriture cible, mais pas de la langue.

31 - BALLARD, M., Le nom propre en traduction, Paris, Ophrys, 2001,p.11
2018 العدد الرابع والعشرون (الجزء الثالث)
()
مجلة كلية التربية- جامعة عين شمس137 
Traduction des référents culturels dans

le roman « le voleur et les chiens » vers le français

de dénomination, "toute modification aboutit, non à une traduction d'un nom propre, mais à un nouveau nom propre. ${ }^{32}$

En cas de noms propres, le traducteur traite les noms propres par la translittération* car les lecteurs de la langue d'arrivée ne connaissent pas le code de la langue de départ.

L'onomastique fait partie de la culture. Les noms propres indiquent le plus souvent l'origine culturelle d'une personne. Pour nous, les noms propres ne sont pas traduisibles. Ils restent comme tels dans la langue d'arrivée. Mais, certains noms propres attirent l'attention. Ce sont les noms propres connotatifs ayant des indicateurs religieux, historiques et mythiques. Dans ce cas, le traducteur essaie de trouver l'équivalence comme en témoigne cet exemple qui existe dans notre corpus :

"وآمنت بأنني لو أرسلته Nabawiyya dans le désert où s'est égaré le مع نبوية إلي الصحراء

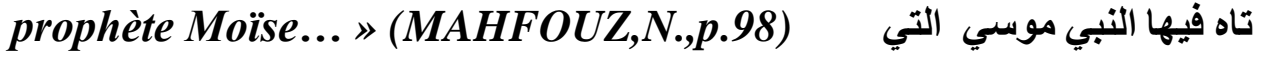
83 "صدي الت 83

Le traducteur n'a pas recourt à l'emprunt et n'utilise pas la translittération (Moussa), par contre, il fonde sa traduction sur l'équivalence de ce nom propre qui est « Moïse ».

Un jour, j'ai rencontré un américain au musée égyptien au Caire, il m'a demandé mon nom " je lui ai dit "Ibrahim" il m'a répondu "Abraham". Je lui répondu "Oui." Parfois, nous cherchons l'équivalence des noms propres qui ont une autre prononciation, mais ce n'est pas vrai dans tous les cas.

Au long du roman, le traducteur a accompli, dans l'acte de traduction, le passage fidèle des identités culturelles des noms 32- KLEIBER, G., Problèmes de référence : descriptions définies et noms propres, Paris, Klincksieck, 1981 In LECUIT Emeline et al., " $\mathbf{L a}$ traduction des noms propres : une étude en corpus ", Corpus [En ligne], 10 2011, mis en ligne le 18 juin 2012, consulté le 30 septembre 2016.
2018
العدد الرابع والعشرون (الجزء الثالث)
()
مجلة كلية التربية- جامعة عين شمس138 
Dr. Ibrahim Abd Elnabi ISSA

propres du texte d'origine dans le système culturel récepteur tout en gardant la fonction de marque d'onomastique arabe, par exemple : Nabawiyya(MAHFOUZ,N.,p.7), Madame Nour, Aliche(Ibid,p.12), Sana(Ibid,p.11.), Bayadha(Ibid,p.10), l'actrice Kawakeb. Pour les mêmes raisons, d'accorder au texte d'arrivée la sonorité arabe, le traducteur reste toujours fidèle à la transposition graphique.

Le traducteur peut choisir la stratégie de transcription phonétique qui consiste dans l'adaptation graphique de certains noms propres, afin de les franciser, comme par exemple : Cheikh Ali Guénidi, Saïd Mahrane.

Dans la traduction littérale le traducteur recourt à la translittération du nom propre du personnage : L'agent Hassaballah,

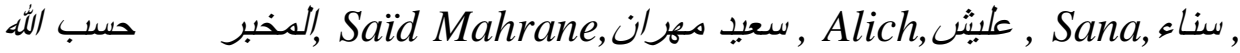
Bayadha, بياظة, Madame Nour, مدام نورن, Cheikh Ali Guénidi, الثيخ علئي

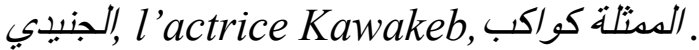

Il est à mentionner que dans le transfert des noms propres, les modifications graphiques n'altèrent point le sens. Les noms propres des textes religieux sont évidemment des culturèmes* pour les Arabes et gardent leur mono-culturalité dans la traduction française. Ces noms propres sont analysables et sont soumis à la naturalisation dans la culture réceptrice par l'application du procédé de traduction littérale, comme par exemple :

Dans le cas de bourreau (عشماوي) (MAHFOUZ,N.,p140..), le traducteur a recours à l'équivalence.

Selon nous, les noms propres sont sujets à tous les procédés de traduction proposés. Dans notre corpus, nous analysons comment le traducteur traite les noms propres tributaires de la société égyptienne.

Le traducteur utilise la transcription en traduisant: (سعيل مهران) par(Saïd Mahrane), (Ibid,p.11), (عليش)par(Alich), (Ibid, p.7), 
Traduction des référents culturels dans

le roman « le voleur et les chiens » vers le français

par(l'agent Hassaballah), (رلمخبر حسب الله) par (Raouf) (Ibid,p.43.) (بناء) par(Sana),(Ibid,p.8), (بياظة)par(Bayadha), (Ibid., p.10), (مدام نور) par(Madame Nour)(Ibid,p.61), ( الشيخ على (1) (الجندي)par(Cheikh Ali Guénidi), et (المثثلة كواكب) par (l'actrice Kawakeb.)

\section{8-1-1-Remarques sur la traduction des noms propres}

La difficulté de traduction des noms propres réside dans quelques points :

- la différence au niveau morpho-syntaxique et phonétique comme en témoignent Saïd Mahrane ( سعيد مهران )Hassaballah( حسب الله). Le système phonétique arabe se différencie de celui de la langue française. Celle-ci ne possède pas les sons (3- h)

- portée connotative de noms propres comme en témoignent le mot arabe (عنتر)qui désigne un nom propre qui se caractérise par la force, la virilité et le courage.

- asymétrie culturelle, il existe des phénomènes culturels inconnus dans d'autres cultures.

- "signification de noms propres (malgré de nombreuses opinions le contestant) qui trouve ses sources et reflet dans : a) l'étymologie du mot en question ; b) son emploi ; c) sa structure qui peut être révélatrice pour le déchiffrement de ses significations implicites ; d) les connotations que le nom propre éveille chez les membres de la langue-culture de départ. ${ }^{33}$

33-PALICZKA, Anna, Nom propre et ses dérivés en traduction, Université de Silésie,2009, p.5. Disponible sur le site : http://el.us.edu.pl/wf/ pluginfile. php/ 271/mod_resource/ content/ 0/ paliczka.pdf

العدد الرابع والعشرون (الجزء الثالث) 2018

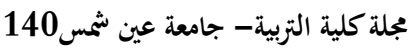


Dr. Ibrahim Abd Elnabi ISSA

- Variation graphique d'un seul nom propre. C'est le cas de (محمد) qui peut être écrit: Mohammed, Muhammed, Mohammet, etc.

Les prénoms et les noms de famille doivent être repris sans modifications.

L'assimilation phonétique et graphique est la solution admise dans le cas de la traduction de deux langues ayant d'origine différente comme le français et l'arabe. Prenons comme exemple Joseph (يوسف). L'assimilation phonético-graphique touche

- les noms propres des personnages religieux, historiques et légendaires comme Moïse (موسي), Jacob(يعقوب), Zeus(زيوس).

- les noms des lieux mythiques et de lieux réels : Louvre (اللوفر) Marseille (مارسيليا)

Malgré la possibilité de traduire les noms propres ayant une signification comme (petit) qui désigne en arabe (صغير), mais le traducteur ne peut le traduire qu'en (بيتي).

En traitant les noms propres, les traducteurs peuvent adopter d'autres techniques ${ }^{34}$ dont :

\section{-Modification radicale}

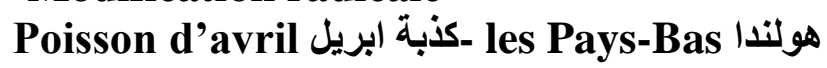

\section{-Traduction élargissante}

Cette traduction recourt à ajouter des mots aux mots de la langue de départ. Le traducteur trouve que la traduction de cible est incomplète. C'est le cas des sigles et des abréviations comme T.G.V(القطار السريع), la Mer Blanche (البحر الأبيض المتوسط)

\section{-Traduction littérale}

Elle peut toucher les noms propres comme le jour SaintValentin( عيد القديس فلانتين أو عيد الحب), les lieux géographiques comme la Mer Rouge(البحر الأحمر).

Dans «le voleur et les chiens» le traducteur a maintenu certains noms tels quels et fait des adaptations pour d'autres. Contemplons :

${ }^{34}$ - Ibid., p. 8

العدد الرابع والعشرون (الجزء الثالث) 2018

مجلة كلية التربية- جامعة عين شمس141 
Al-Hussein , petit-fils du Prophète Muhammad, serait, selon une croyance populaire sans fondement historique, enterré au Caire où il a donné son nom à la célèbre mosquée Sayyidna al-Hussein.

Antara ibn Cheddad : poète et chevalier de l'ère préislamique dont le courage lui a valu de devenir un héros de geste.

«La typologie des noms propres s'agence autour des groupes suivants : 1) les anthroponymes qui incluent les noms de personnes (patronymes et prénoms);

2) les toponymes (les noms de lieux);

3) les ethnonymes ou les gentilés (c'est-à-dire les dénominations des habitants d'un lieu relativement à ce lieu);

4) les zoonymes (noms propres donnes aux animaux) $\gg^{35}$

Selon Nina Cuciuc, "le mythonyme contient les noms propres du domaine folklorique. Les sous-catégories des mythonymes sont les suivantes :

1) les mythoanthroponymes (noms propres des personnages folkloriques);

2) les mythotoponymes comprenant :

(a) les mythohydronymes (les cours d'eau imaginaires) et (b) les mythoronymes (les noms de montagnes imaginaires) ;

3) les mythoethnonymes (dénomination des habitants d'un lieudit imaginaire);

4) les mythozoonymes (noms propres des animaux imaginaires). ${ }^{36}$

En tenant compte de l'aspect phonétique des termes, le traducteur recourt à la translittération du nom propre en francisant son orthographe. Les graphèmes qui n'ont pas d'équivalence en français sont remplacés par des graphèmes qui peuvent reproduire fidèlement les sons de l'alphabet arabe. En ce cas, le récepteur peut facilement prononcer ces termes. Passons maintenant à un autre

35_CUCIUC, Nina, Traduction culturelle: Transfert de culturèmes, Presses Universitaires de France, "La linguistique ", 2011/2, Vol. 47, p.140 36 - Loc.cit

العدد الرابع والعشرون (الجزء الثالث) 2018

مجلة كلية التربية- جامعة عين شمس 142 
Dr. Ibrahim Abd Elnabi ISSA

référent culturel existant dans notre corpus, c'est la toponymie qui s'intéresse à étudier les noms des lieux.

\section{8-2-Les toponymes}

Dans le cas de traduction des toponymes, nous n'avons pas nécessairement besoin d'un changement de forme graphique. « $L a$ translation recouvre quatre cas de figure selon que le nom propre reste inchangé, qu'il est transcrit, translittéré ou traduit. Des combinaisons de ces différents procédés sont aussi possibles. De plus, la forme obtenue par translation interagit avec les caractéristiques morphologiques de la langue cible. Le toponyme étranger, par rapport au français, est soit une forme locale ou endonyme qui est empruntée comme Appenzell, Bregenz, Prater ou Oder, soit une forme traduite appelée exonyme comme Autriche, Saxe, Munich, Porte de Brandebourg ou lac de Constance. Notons que dans la grande majorité des cas, la traduction d'un nom propre est un emprunt. ${ }^{37}$

Le traducteur possède plusieurs procédés pour traduire les toponymes: l'emprunt (écrit en italien, Roma, روما), la translittération(Al Qāhirah, القاهرة), la transcription (Muqattam, المقطح), la traduction littérale qui contient : le calque (White-House, Maison-Blanche, البيث الأبيض), l'adaptation (London=Londres=لندن).

Dans notre corpus, le traducteur a recours à la transcription et la traduction littérale pour traduire les toponymes.

En ce qui concerne la transcription, il traduit (المقطم صد.18) par (Muqqattam, MAHFOUZ,N., p.21) et ajoute aussi une explication en bas de la page: Colline sablonneuse qui surplombe l'est du Caire. Il ne veut pas perdre le sens, en même temps il respecte l'incompréhension du lecteur étranger qui n'a pas d'arrièreplan culturelle de ce lieu. Il met une majuscule au début de tous les

37 - GRASS, Thierry "La traduction comme appropriation : le cas des toponymes étrangers." Meta 514 , 2006, p. 662

العدد الرابع والعشرون (الجزء الثالث) 2018

()

مجلة كلية التربية- جامعة عين شمس 143 
Traduction des référents culturels dans

le roman « le voleur et les chiens " vers le français

lieux. Dans les exemples suivants, le traducteur a recours à la transcription :

Exemple(1) :

Rue Negmeddine, derrière le cimetière شارع نجم الدين وراء قرافة باب de Bab el-Nasr. (Ibid,)

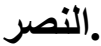

Exemple(2) :

Et que cela s'est passé dans le وان ذلك كان في صحراء زينهم désert de Zeinhom. (Ibid.,p.69)

صـ58.

Nous remarquons que le traducteur n'utilise pas la traduction littérale dans l'exemple (1), il aurait pu le traduire comme : «Rue Étoile de la Foi derrière le cimetière de la Porte de la Victoire .» Nous trouvons d'autres cas de traduction par la transcription dans notre corpus: le traducteur traduit (شارع نجم ) (للدين) par (la rue

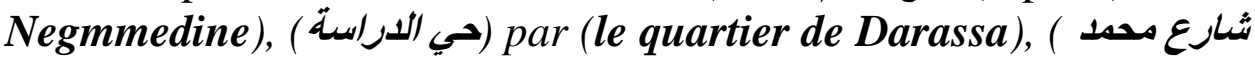
(علي) par (Avenue Mohammed Ali),(صحراء العباسية) par ( Le désert d'Abbassieh) (Ibid.,p.64.), (حي روض الفرج) par (Rod el-Farag) (MAHFOUZ,N.,p.127..), (في قبور البلينا) par (au cimetière de Balyana) (Ibid.,p104..),(جسر عباس)par (pont Abbas) (Ibid.,N.,p.47.)et (عطفة الصرفي) par (le passage Seirfi), (Ibid.,p.9.). Le traducteur ajoute pour certains lieux une explication comme : Balyana (Bourg de Haute-Egypte, au sud de Sohag.) et Rod elFarag (Quartier populaire du Caire)

En ce qui concerne la traduction littérale, il traduit (القلعة) par (la Citadelle) (Ibid.,N.,p71..), (الفراندا) par (la Véranda). Dans le cas de la Place de la Citadelle, nous voyons que le traducteur ait dû recourir à l'emprunt.

\section{8-3-Les magasins}

Dans le monde entier, il y a des branches de magasins universaux. Nous, les Égyptiens, prononcent le nom de ces magasins d'une façon quasi-pareille à celle de l'origine de ces 


\section{Dr. Ibrahim Abd Elnabi ISSA}

magasins. C'est le cas de magasins comme carrefour, city stars, etc.

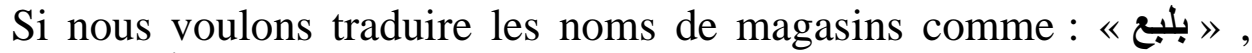

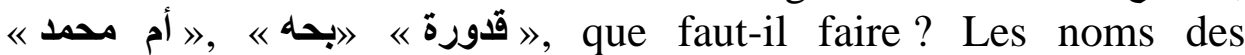
magasins sont difficiles à être traduits. Les lecteurs français ne comprennent pas les noms de ces magasins. Le traducteur va utiliser l'emprunt avec la transcription. Il en va de même dans les exemples de notre corpus, le traducteur a recours à la transcription en traduisant « العجاتي 》 en l'écrivant «Ayati ».

«Un vrai festin ! Je t’apporte un وليمة ! معي العجاتي وتسباس" ومانولي!" صـ.84 depas digne d'Ayati, de Tsepas et

de Manoli réunis. » (Ibid.,p. 101.)

Ces trois magasins n'existeraient pas en France et c'est pourquoi le traducteur doit transmettre le contenu culturel. Il trouve qu'il soit nécessaire d'ajouter une explication en bas de la page : "Grands restaurants du Caire ». La transcription ne transmet pas les mêmes connotations. Mais l'explication rend le contenu culturel de ces trois magasins compréhensible pour les lecteurs français. Il nous convient de mettre en relief les noms des magasins qui sont connus dans tout le monde. Ce genre de magasins sont faciles à être traduits comme LIDL ou Carrefour.

\section{8-4-Les journaux et les revues}

Comment peut-on traduire les noms des journaux ? Il y a des journaux ayant de notoriété internationale comme «le Figaro», «The Times», « The Guardian » et « Le Monde». Dans le monde arabe, on les traduit : الوموند-ذا تايمز-الجاريان-لويجارو en témoignent ces deux titres de journaux arabes : 
Traduction des référents culturels dans

le roman « le voleur et les chiens » vers le français

"صحيفة "الوفيجارو": هل مازال بوتفلبة بحكم الجزائر؟!"

"Bouteflika gouverne-t-il encore l'Algérie ? " ${ }^{39}$

"في استفتاء لجريية "ليكيب" الفرنسية: فرنسا الأكثر جاهزية لاستضافة "كان 2015 $40 . "$

«La France est prête à accueillir CAN 2015. »

Nous remarquons que les journalistes arabes ne traduisent pas les noms des journaux même si ceux-ci peuvent être traduits comme par exemple le journal (l'équipe) qui peut être traduit en arabe par (الفريق). Ils utilisent l'emprunt avec la transcription en

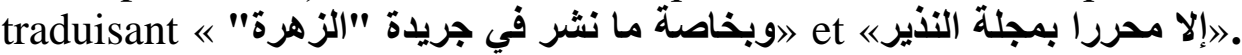
Dans notre corpus, le traducteur préfère la transcription et la translittération en citant "al-Zahra" (MAHFOUZ,N., p.101.)et "alNadhir" (Ibid.,p.33..) bien que ces journaux puisent être littéralement et respectivement traduits par «La fleur » et «L'avantcoureur.» Le lecteur français peut seulement s'intéresser au nom du journal et de la revue sans comprendre le sens de ce contenu culturel. Dans notre corpus, le traducteur a aussi recours à la transcription en traduisant "جريية أبو الهول (Ibid.,p.82.)

38_Ce titre d'article est tiré du journal arabe (almugtama, جريدة المجتمع), le 12 Novembre, 2015. Disponible sur le site : http://mugtama.com/translations/item/25632-2015-11-12-05-18-11.html. (Consulté: le 25-6-2016)

${ }^{39}$-Ce titre d'article est tiré du journal «LeFigaro » et écrit par Adam Arroudj Disponible sur le site :http://www.lefigaro.fr/international/2015/11/09/01003-20151109 ARTFIG 00236-bouteflika-gouverne-t-il-encore-l-algerie.php (Consulté le 16-8-2016)

40. Ce titre d'article est tiré du journal arabe(assabahnews, الصباح نيوز), le 13 Novembre, 2014. Disponible sur le site :

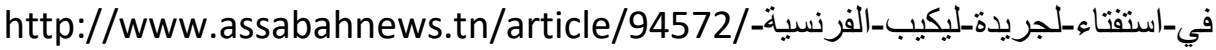

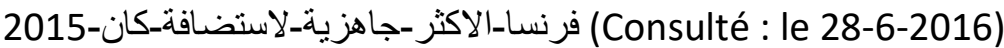

العدد الرابع والعشرون (الجزء الثالث) 2018

()

مجلة كلية التربية- جامعة عين شمس146 


\section{8-5-Les professions}

Y a-t-il des professions existantes dans une société et inexistantes dans une autre? Comme en Égypte, dans le passé, celui qui vend de l'eau (السقا) qui signifie « le vendeur de l'eau ». De même, le mot (messahharâti: المسحراتي)qui signifie celui qui durant Le Ramadan, passe dans les quartiers pour réveiller les musulmans avant l'aube, afin qu'ils prennent leur repas d'avant jeûne. Le traducteur dans ce cas est obligé de recourir à l'explication en bas de la page. Prenons comme exemple :

«Mon père était omdeh. "

Il rectifie doucement : "C'était le domestique de l'omdeh. » (Ibid, p123.)

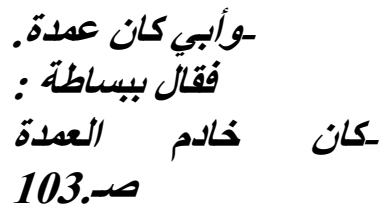

En ce qui la profession (omdeh : العمدة), de notre corpus, le traducteur présente, en bas de la page, l'explication : sorte de maire au pouvoir de fait considérable. Il sait bien que la langue cible ne contient pas l'équivalence de cette profession. "Lorsqu'il n'y a pas d'équivalence totale entre les deux langues, l'emprunt reste parfois la seule option. $»^{41}$

Dans un autre exemple, le traducteur a utilisé l'équivalence parce que cette profession n'existe pas en France comme en témoigne cet exemple :

"La diseuse de bonne aventure. » (MAHFOUZ,N., " ضاربة" p.114.)

الودع" ص.94. (الوبه :

Nous remarquons qu'il n'utilise pas cette nomination : Celle qui lance de Coquillage (ou lâche les cauris). Il s'agit de la caurimancie «divination par l'interprétation de la disposition de

41 - FUENTES, Sandrine. LA TRADUCTION DES NOMS DE PROFESSION DANS UN SYSTÈME DE DICTIONNAIRES ÉLECTRONIQUES COORDONNÉS (ES-FR), Verbum,2016. 7.7: 66-83., p.80. Disponible sur http://www.zurnalai.vu.It / verbum/ article/ view/10287/8159(Consulté le 15-03-2018)

العدد الرابع والعشرون (الجزء الثالث) 2018

مجلة كلية التربية- جامعة عين شمس147 
Traduction des référents culturels dans

le roman « le voleur et les chiens » vers le français

cauris jetés sur le sol. Dans un autre exemple, nous trouvons que le traducteur préfère la transcription comme en témoigne : «Nous dépendons d'el-wayli. » (Ibid.,p.148)

Nous trouvons que les lexicologues commencent à mettre certains mots étrangers dans les dictionnaires comme en témoignent les mots : le muezzin et le cheikh qui sont aussi présents dans notre corpus.

"Le Cheikh réplique calmement : Et Eقال الشيخ بهويء : - وياب la porte du Ciel, comment l'as-tu 21 السماء كيف وجلته؟ "صلئ trouvée ? »(Ibid., p.25)

Parmi les professions qui sont présentes dans les pays islamiques, nous constatons la profession du muezzin. Cette dernière n'est pas dans d'autres pays. C'est pourquoi, nous trouvons que le traducteur recourt à l'emprunt comme le cas de notre corpus : "Au moment où le muezzin appelle à la وعند آذان الفجر سمع الباب"

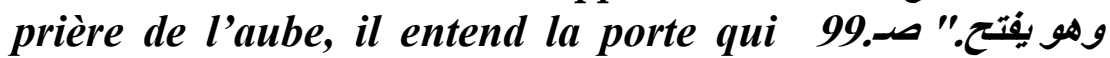
s'ouvre. » (Ibid.,p.121)

\section{8-6- Les rites religieux et les fêtes}

Les rites religieux et les fêtes occupent une grande place dans la vie quotidienne et constituent une partie importante de la culture partagée par les membres d'une communauté linguistique. Ce contenu culturel et les systèmes linguistiques qui le matérialisent les rendent très difficiles à traduire. "Les mêmes mots, les mêmes phrases, les mêmes situations ont parfois des résonances différentes dans deux langues de culture : ce que perçoit le lecteur étranger n'est pas nécessairement ce que nous fera percevoir une traduction exacte $\gg .{ }^{42}$ Nous trouvons dans un tel pays des rites ou des fêtes qui

*-L’Achoura est le dix (du mois de Mouharram) est un événement religieux des pays musulmans. 
Dr. Ibrahim Abd Elnabi ISSA

n'existent pas dans un autre pays. C'est le cas par exemple du (Cham Ennessim, عاشوراء) اءم النسيم). et (L'Achoura*, Le traducteur recourt à la fois à l'emprunt et à l'explication.

"Très souvent, les fêtes françaises sont associées systématiquement à un autre mot. Ainsi Pâques évoque instantanément les cloches, les lapins, les poules, les poissons et les oufs en chocolat, l'agneau pascal ; le premier Mai évoque le muguet ; la Toussaint les chrysanthèmes, le cimetière ; la Chandeleur les crêpes ; Noël le sapin, la bûche ; etc. Si le traducteur n'associe pas, comme par réflexe, les deux composants du couple, il sera très facilement induit en erreur. La traduction passe automatiquement par l'interprétation en langue-source, par un effort de compréhension qu'il faut ensuite recomposer avec des moyens linguistiques qui appartiennent à une autre langue. Dans le cas qui nous intéresse, pour une compréhension véritable de toute la portée d'une fête, les connotations que cette fête suscite doivent être connues du traducteur. $»^{43}$

Dans notre corpus, le traducteur emploie l'emprunt pour traduire le mot (حلقة الأكر) par (le cercle de Zikr ) (MAHFOUZ,N.,p.23) et ajoute une explication en bas de la page pour faire comprendre le lecteur français le sens de ce rite religieux répandu en Égypte en écrivant :cérémonie soufie visant à atteindre un état d'exaltation mystique par la répétition du nom de Dieu et le balancement du corps sur un rythme cadencé. Si le traducteur

42-FICHOU, J-P., Enseigner les civilisations, Paris, PUF, 1979, p. 45.In Real, E., Jiménez, D., Pujante, D. y Cortijo, A. (eds.), Écrire, traduire et représenter la fête, Universitat de València, 2001, pp. 723-733, I.S.B.N.: 84-370-5141-X.

43- SORIANO, Ascensión Sierra, Les fêtes au fil des mois : problèmes de traduction, Universitat de València, 2001, p.724

العدد الرابع والعشرون (الجزء الثالث) 2018

()

مجلة كلية التربية- جامعة عين شمس 149 
méconnaît les éléments connotés de la langue source, il sera induit en erreur.

Pour les rites et les fêtes, nous remarquons des inéquivalences interlinguistiques. Le traducteur doit en rendre compte. Parmi ces inéquivalences, nous citons :

a- Les dates des fêtes ne sont pas identiques. Citons, par exemple, la date de la Fête des mères qui varie d'un pays à l'autre. La majorité a choisi de la célébrer en mai. En France, à Monaco et dans plusieurs pays d'Afrique francophone, elle est célébrée le dernier dimanche de mai. En Belgique, au Canada, en Suisse et dans de nombreux autres pays, la Fête des mères est célébrée le deuxième dimanche de mai. ${ }^{44}$

b- La date et la coutume varient : En France, le poisson d'avril (le premier avril), en Égypte كذبة إبريل (le premier avril), en Espagne et en Amérique Latine une fête comparable, qui tombe cependant le 28 décembre. C'est le « massacre des Innocents » ou « jour des saints innocents »

c- La fête n'existe pas dans un pays : le mouled (المولد),consacré à certains fidèles, existe en Egypte ou le «al-mawlid annabawîy », (المولد النبوي) existe dans le monde islamique.

d- Le saint invoqué n'est pas si important dans l'autre culture: La Saint-Nicolas le 5 ou le 6 décembre et Jeanne d'Arc, 30 mai.

Revenons à notre corpus, nous trouvons que le traducteur utilise l'emprunt en traduisant (دقيق العيد صـ(1) par la farine de l'Aïd (MAHFOUZ.N., p.9) Nous connaissons bien que les musulmans fêtent deux manifestations festives au long de l'année : Aïd al-Fitr ou Aïd el-Fitr qui signifie une fête de la rupture et Aïd al-Adha qui signifie une fête du sacrifice. Puisque la plupart de la société

44 - Cf. https://fr.wikipedia.org/wiki/Fête des Mères consulté le 18-04-2018
2018 العدد الرابع والعشرون (الجزء الثالث)
()
مجلة كلية التربية- جامعة عين شمس 150 
Dr. Ibrahim Abd Elnabi ISSA

française est catholique, on ne fête pas publiquement ces deux manifestations. Les Français ne comprendraient pas ce qui veut dire la farine de l'Aïd dont les peuples musulmans, en particulier, les arabes, font les desserts comme (كحك أو كعثك) qui signifie "le kâak ou plus correctement $\boldsymbol{k a}$ 'ak (arabe : littéralement "gâteau " en arabe classique, est un terme qui peut désigner plusieurs pâtisseries maghrébines et orientales sous forme

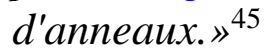

Certaines fêtes n'ont pas d'équivalents dans la langue-cible, d'où le besoin de les expliquer au lecteur. La traduction d'un texte en français devra inclure une explication.

\section{8-7-Les nourritures et les boissons}

Les nourritures et les boissons ont un impact sur la langue de chaque pays. Les plats varient d'un pays à l'autre. Étant bilingue et bi-culturel, le traducteur doit avoir les compétences qui lui permettent de combler les lacunes de la langue d'arrivée. Il ne traduit pas seulement les mots, mais aussi la culture. Après la phase de compréhension vient la phase de réexpression. Comment peut-il traduire un phénomène absent dans la culture-cible. "Toutefois, il faut garder à l'esprit que si le lecteur de la traduction peut être ignorant, il n'est pas pour autant imbécile. ${ }^{46}$.

Parfois, nous pouvons trouver des noms de nourriture et de boissons qui n'ont pas de correspondance dans la langue ou la culture d'arrivée. Il y a des éléments ou des aliments inhabituels qui frappent le lecteur. Le traducteur doit les présenter de façon compréhensible pour son nouveau lectorat.

45 - https://fr.wikipedia.org/wiki/Ka'ak (Consulté le 20-04-2018.)

46-LEDERER, Marianne, La traduction aujourd'hui, Paris: Hachette, 1994, p.123 In : Camilla Skilbred, Le transfert du culturel dans la traduction de Poisson d'or de Le Clézio, Université d'Oslo, 2005, p.39

العدد الرابع والعشرون (الجزء الثالث) 2018

()

مجلة كلية التربية- جامعة عين شمس151 
Dans notre corpus, le traducteur préfère l'addition. Celle-ci est souvent une explication, jugée nécessaire par le traducteur, pour rendre le texte plus compréhensible. Ces additions se trouvent souvent dans une note en bas de page. On trouve aussi des additions parfois peu nécessaires. Le traducteur traduit (الشربات) par (le charbat), (MAHFOUZ,N.,p.10.) et ajoute une explication : "Boisson au sirop de fruits que l'on offre traditionnellement dans les occasions heureuse. » Il traduit( بسطرمة ) par (Basterma) (Ibid.,p.39.) et ajoute : «saucisson de bœuf à l'ail. » Puis, il traduit (الطحينة) par (La tahina) et ajoute une explication: "Mets d'accompagnement à base de sésame. »Ces aliments et ce boisson n'ont pas de traduction. Par contre, pour pouvoir comprendre le sens de la phrase, il fallait ajouter une autre explication.

Le traducteur utilise l'emprunt dans les exemples précédents qui nous montrent le respect de la langue source. Le traducteur a recours à cette procédure car il n'y a pas d'équivalence en français, raison pour laquelle il a fait une explication de bas de page. Selon Dubois, dans le dictionnaire de linguistique, l'emprunt se passe "quand un parler A utilise et finit par intégrer une unité ou un trait linguistique qui existait précédemment dans un parler $B$ (dit langue source) et que A ne possédait pas; l'unité ou le trait emprunté sont eux-mêmes qualifiés d'emprunts. L'emprunt est le phénomène sociolinguistique le plus important dans tous les contacts de langues. ${ }^{47} \mathrm{Si}$ le traducteur néglige l'explication de ce mot, il perdra son sens dans la langue-cible. La traduction n'est pas seulement le passage d'un message dans une langue source vers une langue cible, mais aussi un passage d'un phénomène ou une aire socioculturelle à une autre. De plus, Umberto Eco constate qu'il faut décider si «en traduisant, il faut amener le lecteur à comprendre l'univers culturel

${ }^{47}$-DUBOIS ,Jean, Op.cit., p.177

العدد الرابع والعشرون (الجزء الثالث) 2018

مجلة كلية التربية- جامعة عين شمس152 
Dr. Ibrahim Abd Elnabi ISSA

de l'auteur ou bien s'il faut transformer le texte original en l'adaptant à l'univers culturel du lecteur» 48 .

Puisque nous sommes devenus en petit village grâce au développement sur le niveau de communication, de moyens de transport, de satellites, de réseaux sociaux, d'internent, de portable, ...etc., nous pouvons trouver les mêmes nourritures et les mêmes boissons dans le monde entier, par les exportations et les importations. Mais, ce qui est différent d'un pays dans un autre pays, c'est les recettes de ces aliments et de ces boissons. Citons : (Sobia, mes'aa, Koshri, Homesseya, Foul Nabit, ...etc.) Dans le cas des aliments et des boissons qui dépendent de recettes comme

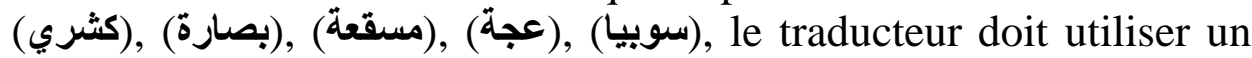
emprunt car ces nourritures n'ont pas d'équivalence en France. Il les traduit respectivement: (Koshri),(Biçara),(Mis'aa),(Igaa), (Sobia),..etc. Il ajoute en bas de la page une explication de ces plats. De même, les plats les plus connus se transfèrent sans modification. Bien qu'ils apparaissent dans un seul pays, ils gardent leur nom comme: le pizza qui est un des mets de la cuisine italienne, le humbarger qui fait référence à la ville de Hambourg, en Allemagne. Ces plats sont faciles à être traduits.

Selon nous, ce sont des plats qui se composent d'ingrédients, ils sont comme les fabrications qui ont un brevet d'invention. C'est pour quoi, nous les transmettons le plus souvent sans remaniement. C'est le cas des modèles de voitures (Fiat, Mercedes, Volvo, Peugeot, Ford) ou des modèles de vêtements(aloha, jupe, minijupe, paréo, etc.)

Dans notre corpus, en ce qui concerne « Doum », nous trouvons que le traducteur ait commis une erreur parce que c'est une plante qui s'appelle Hyphaene .

« en grignotant un fruit de doum.» ويقضم دومة.22

48-UMBERTO, ECo, Op.cit., p. 202
2018
العدد الرابع والعشرون (الجزء الثالث)
()
مجلة كلية الزبية- جامعة عين شمس153 


\section{(MAHFOUZ,N.,p.26.)}

Le traducteur a recours à l'emprunt en ajoutant une explication bien que ce terme ait une correspondance dans la langue d'arrivée. Il fallait remplacer « un fruit de doum » par « hyphaene.»

\section{8-9-Les vêtements}

Parfois les vêtements sont liés à la culture. Dans les pays de Golf, les citoyens préfèrent porter une gallabieh. Les indiens portent kurtapigiama, sari, dhoti ou longhi, churidar ou salwar-kameez , une dupatta, le salwar et le churidar kurta. En Égypte, au $19^{\mathrm{e}}$ siècle, on porte tarbouche (un fez). Maintenant, certaines femmes portent un niquab. Donc, chaque pays a ses habitudes vestimentaires.

"Parmi les difficultés de la traduction les plus souvent mentionnées, on trouve les problèmes dits culturels. Les objets ou les notions appartenant exclusivement à une culture donnée ne possèdent pas de correspondances lexicales dans la civilisation d'accueil et si on arrive à les exprimer néanmoins, on ne peut compter sur le lecteur de la traduction pour connaître avec précision la nature de ces objets et de ces notions; les habitudes vestimentaires ou alimentaires, les coutumes religieuses et traditionnelles mentionnées par l'original ne sont pas évidentes pour le lecteur de la traduction. Il ne s'agit pas seulement de savoir quel mot placer dans la langue d'arrivée en correspondance à celui de la langue de départ, mais aussi et surtout de savoir comment faire passer au maximum le monde implicite que recouvre le langage de l'autre. "49

Mais comment le traducteur traduit-il les vêtements qui n'existent pas dans son pays ? Le traducteur utilise l'emprunt comme le cas de la gallabieh(Ibid.,p.12.). Le récepteur aurait besoin d'une traduction

49 - LEDERER, M., Op.cit., p.122

العدد الرابع والعشرون (الجزء الثالث) 2018

مجلة كلية التربية- جامعة عين شمس154 
visuelle, il s'agit d'une traduction qui est accompagnée par une photo ou par une explication. Dans la traduction des vêtements, le traducteur a recours à l'adaptation phonétique. Dans notre corpus, le traducteur ne trouve pas de difficulté pour traduire certains vêtements car les Egyptiens, à leur tour, ont déjà emprunté ces nominations à des langues étrangères comme en témoigne cet exemple :

«A deux pas seulement, vêtu d'une longue robe de chambre dans laquelle il a l'air d'un géant. » (MAHFOUZ,N,p.50)

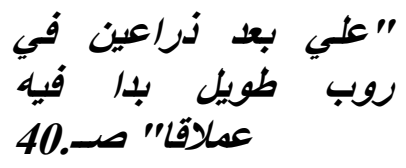

Le traducteur ne trouve aucun problème parce que les Égyptiens utilisent le mot robe qui n'est pas d'origine arabe. Depuis longtemps, les Égyptiens , utilisent robe, minijupe,pantalon, jupe, etc. Ce sont des mots de vêtements d'origine étrangère. Parmi ces vêtements, nous trouvons aussi : pantalon, tunique, jupe, minijupe, casquette, chapeau, sandales, bottes, écharpe, etc. Mais, nous devons confirmer que "Le degré d'altérité de l'image que la culture réceptrice crée par rapport à la culture-source est du aux difficultés qui résultent des différences existant entre les deux langues en contact. ${ }^{50}$ Passons maintenant à une autre difficulté qui pose problèmes dans le cas de traduction, c'est les us et les coutumes.

\section{8-10-les coutumes et les mours}

Obtenant une bourse post-doctorat de six mois en France en 2014, en particulier à Paris, nous nous étonnons du «videgreniers. " C'est la première fois que nous rencontrons un tel événement. Il s'agit d' un rassemblement populaire au cours duquel des particuliers exposent les objets dont ils n'ont plus l'usage, afin de s'en départir en les vendant aux visiteurs.

50 - CUCIUC, Nina, Op.cit., p. 138.
2018
العدد الرابع والعشرون (الجزء الثالث)
()
مجلة كلية التربية- جامعة عين شمس155 
Traduction des référents culturels dans

le roman « le voleur et les chiens » vers le français

En France, «les étrennes » sont des cadeaux offerts obligatoirement en début d'année, au début du mois de janvier. " $A$ l'origine, les étrennes étaient versées par l'employeur au personnel de maison pour le remercier de la qualité de son service durant l'année passée (le calendrier des pompiers, des éboueurs ou celui du facteur est certainement un héritage de ce passé). Désormais, ce sont les parents ou grands-parents qui les offrent à leurs enfants ou petits-enfants. » 51

En Égypte, (عيدية: Eidia) est un cadeau traditionnellement offert aux jeunes par des parents plus âgés et des amis de la famille dans le cadre de la célébration des deux fêtes musulmanes, Aïd al-Fitr et Aïd al-Adha.

Chaque pays a donc ses traditions et ses coutumes qui n'existent pas dans un autre pays. Aux Pays-Bas, il ne faut pas offrir comme cadeau un objet pointu. En Hongrie, boire de la bière ou trinquer peut porter de mauvais souvenirs aux Hongrois. Pour les russes, les fleurs jaunes signifient la rupture ou la tromperie. En Égypte, on fête le nouveau-né, on jette du sel. Dans notre corpus, nous trouvons نقطة : certains coutumes qui n'existent pas en France. Nous en citons qui est un argent donné comme cadeau aux maries le jour de la noce.

\section{"Zayyat me fait cadeau pour l'occasion d'un billet de dix livres. » (MAHFOUZ,N.,p.98)}
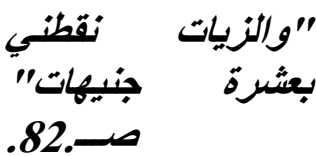

Le traducteur devait expliquer en bas de la page que les parents de mariés ou leurs amis leur offrent en cadeau de l'argent que les Égyptiens appellent «قطة \. Le jour de la noce, les coutumes peuvent être différentes: jeter des grains surtout du riz en France,

51-http://cladelcroix.mondoblog.org/us-coutumes-nouvel-an-francais/ consulté le 20-04-2018

العدد الرابع والعشرون (الجزء الثالث) 2018

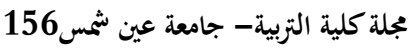


jeter du sel en Egypte.Le traducteur doit connaître ces us et ces mœurs pour bien traduire le texte. Ces coutumes peuvent aussi renfermer les gestes des mains, des doigts, des yeux, du nez, des sourcils, de la tête et des épaules.

\section{8-11-Les interjections}

L'interjection est un mot invariable qui permet au sujet parlant d'exprimer son émotion :colère, joie, douleur, surprise,etc. Pour traduire les interjections en langue d'arrivée, "le traducteur doit faire preuve de créativité [...] car il faut qu'elles soient adaptées à la situation " et qu'elles respectent "le plus possible le ton et le registre de langue utilisés par les personnages .»52 Comment le traducteur du roman traite-t-il les interjections? Prenons ces exemples:

\section{Exemple(1) :}

Saïd...quelle surprise!

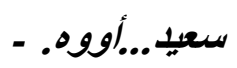

Exemple(2):

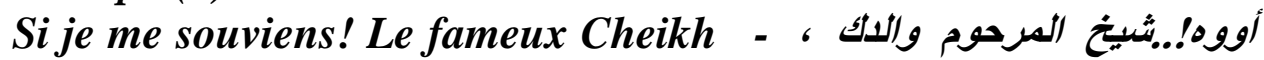

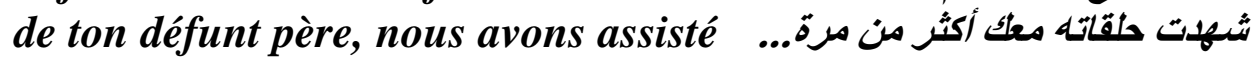
à ses cérémonies plus d'une fois.

Exemple(3) :

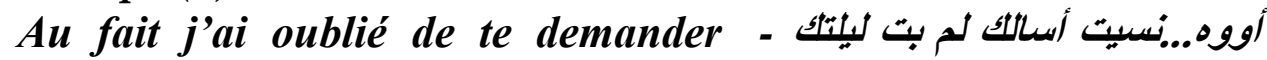
pourquoi as-tu passé la nuit chez le علد الشيخ علي:

Cheikh Ali?

L'auteur, Naguib Mahfouz, emploie à plusieurs reprises l'interjection (أووه). Mais, chaque fois, cette interjection contient un sens différent. Dans la phrase(سعيل ..أودو), il s'agit d'une émotion de

52-MERGER, M.-F., Les onomatopées et les interjections dans la bande dessinée Titeuf et leurs traductions en italien,2012, p.25 In J. Podeur (dir.), Tradurre il fumetto/ Traduire la bande dessinée (pp. 13-28). in TALLARICO, Giovanni. Stratégies culturelles dans la traduction des livres pour enfants: le cas de Geronimo Stilton. Parallèles, 2015, p.100.
العدد الرابع والعشرون (الجزء الثالث) 2018
()
مجلة كلية التربية- جامعة عين شمس 157 
Traduction des référents culturels dans

le roman «le voleur et les chiens » vers le français

surprise, c'est pour quoi le traducteur a employé l'équivalence: quelle surprise. Dans l'autre phrase( أووه..شيخ العرحوم والدك), il s'agit d'une émotion de la concentration. Le traducteur a préféré l'équivalence : "Si je me souviens! » L'interjection de la dernière phrase(أووه...نسيث أسالكك) exprime l'émotion de l'oubli: Au fait j'ai oublié de te demander.... Cela nous montre que la même interjection peut exprimer plusieurs émotions.

Les interjections sont considérées "comme plus particulièrement sensibles à la culture du pays, en raison d'interdits possibles, du sentiment religieux variable et, par voie de conséquence, de la richesse relative des langues source et cible $»^{53}$

\section{8-12-Les expressions figées}

Les expressions figées sont considérées comme des suites de mots dont les éléments sont inchangeables. Elles contiennent par exemple les proverbes, les expressions idiomatiques, les locutions ,etc. Le traducteur peut littéralement traiter ces expressions figées. Les expressions figées "sont source de nombreuses difficultés lors de l'apprentissage d'une langue étrangère ou lors d'une traduction (qu'elle soit manuelle ou automatique).Néanmoins, elles ne font l'objet que de quelques dictionnaires bilingues sans prétention scientifique, et elles ne sont pas au centre d'études de linguistique comparée. Il serait donc du plus haut intérêt que des lexiquesgrammaires bilingues d'expressions figées soient développés. »54 Le traducteur ne doit pas les négliger car " ignorer ces constructions revient à ignorer une bonne partie du langage. ${ }^{55} \mathrm{Il}$

${ }^{53}$-Richet, B. Quelques données et réflexions sur la traduction des interjections, Arras: Artois Presses Université 2001 p.89

54- DANLOS, L., Les expressions figées, Langages $n^{\circ} 90$, Paris, Larousse, 1988,p.6

55. DANLOS, L., " La morphosyntaxe des expressions figées ", Langages, 63,1981, p.53

العدد الرابع والعشرون (الجزء الثالث) 2018

مجلة كلية التربية- جامعة عين شمس158 
Dr. Ibrahim Abd Elnabi ISSA

faut donc maîtriser la culture et toutes ses apparences pour que la traduction réussisse. "Les expressions figées reflètent la culture, comment prendre en compte cette dimension pour une "meilleure traduction $» ?^{56}$

Les expressions figées sont donc une partie de la culture de chaque société. Elles ont besoin d'une différente stratégie dans le processus de traduction. "Maîtriser une langue, c'est maîtriser une culture et cela passe nécessairement par la maîtrise des expressions figées. Cet apprentissage culturel va bien au-delà des connaissances linguistiques, traditionnellement constituées de la phonologie, la syntaxe et le lexique et ne peut se réduire à un simple inventaire lexical. Le locuteur natif ne se rend pas toujours compte de l'idiomaticité de sa langue maternelle, ce qui peut provoquer des erreurs de traduction. ${ }^{57}$ Passons maintenant à analyser certains types des expressions figées qui sont existantes dans notre corpus :

\section{8-13-Les proverbes et les maximes}

Comment peut-on traduire le proverbe de la langue-source à la langue-cible? Le proverbe est omniprésent dans toutes les langues. "Une phrase douée d'une autonomie lexicale qu'on peut insérer comme telle dans un contexte. ${ }^{58}$ Le proverbe est considéré comme une parémie. Il est une expression figée caractérisée par sa forme, ses rimes, son rythme. La traduction littérale des proverbes

56 - VAGUER Céline, Expressions figées et traduction : langue, culture, traduction automatique, apprentissage, lexique , 2014. Disponible sur le site : https://hal.archives-ouvertes.fr/hal-00980140, p. 2

57 - Ibid., p.4

58_ BURGER, H., Phraseology: An international handbook of contemporary research, Germany: Braunschweig, 2007 p. 101 in Bela Glonti Le phénomène des parémies et le problème de leur traduction ou Comment "dire» une culture dans une langue étrangère, Université d'État Ilia, Tbilissi, Géorgie, 2014. Disponible sur le site : http://ojs.iliauni.edu.ge/index.php/eish/article/view/64/50

2018 العدد الرابع والعشرون (الجزء الثالث)

()

مجلة كلية الزبية- جامعة عين شمس159 
Traduction des référents culturels dans

le roman « le voleur et les chiens » vers le français

est ridicule, c'est pourquoi Darbelnet a choisi l'équivalence pour résoudre le problème de la culture des proverbes. Il est à noter que la traduction littérale des proverbes nous amène à l'échec et à l'incompréhension. La phraséologie comprend toutes les séquences figées dont les combinaisons sont stables et indissociables. Elles n'acceptent aucun remaniement. Le proverbe est à la tête des expressions figées à des référents culturels. Dans le monde arabe, le verset peut être employé comme un proverbe. Citons cet exemple du corpus :

\section{"Combien faible est celui qui demande et بعف الطالب والمطلوب. celui qui \\ صـ22} sollicité.»(MAHFOUZ,N.,p.27)

Le traducteur a ajouté une note en bas de page. Il s'agit d'un verset du Saint Coran : Coran,XXII,73. Parfois, le traducteur se trouve dans une affaire très facile quand il traduit certains proverbes. Mais quand ? si le proverbe est identique dans les deux langues (L1 et L2). Prenons comme exemples : les murs ont des oreilles(الحيطان لها ودان) et loin des yeux, loin du cœur(Ibid.,p.97.) (بعيد عن العين ،بعيد عن القلب). Ce rapprochement est aléatoire. Le signifié et le signifiant sont identiques dans ces deux proverbes. Il est rare que la traduction littérale d'un même terme donne lieu à un double sens.

Nous trouvons que le traducteur commet une erreur en traduisant le proverbe arabe(لا تنخدع بالمظاهر) par (Ne sois pas abusé par les apparences). Il n'écrit pas l'équivalence correcte de ce proverbe qui est : «Il ne faut pas se fier aux apparences. » Il en va de même quand il traduit (خير البر عاجلة) comme(la charité ne se fait pas prier) (Ibid.,p.47.). Malgré l'authenticité du sens, nous trouvons qu'il n'utilise pas l'équivalence correcte de la langue cible dans laquelle nous trouvons ( le plus tôt sera le mieux.) 


\section{8-14-Les expressions idiomatiques}

Les expressions idiomatiques occupent une place très importante dans toutes les langues. Il n'est pas nécessaire qu'elles sont similaires dans les langues. Certaines sont similaires et d'autres différentes. Personne ne peut les négliger notamment dans le domaine de la traduction: "Ignorer ces constructions revient à ignorer une bonne partie du langage. ${ }^{59} \mathrm{Si}$ le traducteur les traduit littéralement, le récepteur ne comprendra rien. Celui-là doit être biculturel pour bien jouer son rôle.

En traduisant un texte, le traducteur ne rapproche pas seulement deux langues, mais aussi deux cultures. Pour la réussite de la traduction, il prend en considération les divergences socioculturelles entre les communautés linguistiques et les différentes connotations. Les facteurs culturels jouent un rôle très important dans le processus de la traduction. Le traducteur doit respecter l'authenticité culturelle de la langue de départ et de la langue d'arrivée. Une fois, nous demandons aux étudiants égyptiens dans le département de français de traduire l'expression idiomatique arabe (علي رأسه ريشد), ils traduisent littéralement cette expressions (Sur la tête, il existe une plume). Le récepteur français qui va lire cette traduction ne comprendra pas ce qu'ils traduisent. Mais, il s'agit que celui qui nuit aux autres se sent coupable. Inversement, nous leur demandons de traduire le proverbe (Acheter un chat en poche) comme (اشتري قط في جيبه). Mais le proverbe signifie : c'est conclure un marché sans voir l'objet de l'acquisition et sans en connaître la valeur ou bien terminer une affaire sans l'examiner. " Le problème est que la connaissance du monde n'est pas la même chez les lecteurs du texte cible que chez le public du texte original et

59-DANLOS, L., "La morphosyntaxe des expressions figées ", Op.cit.," p.53-74. 
Traduction des référents culturels dans

le roman « le voleur et les chiens » vers le français

que souvent les 'signifiants' des culturèmes spécifiques sont vides de sens pour ceux qui n'ont pas vécu les phénomènes désignés. "60

Revenons à notre corpus, nous remarquons que le traducteur à plusieurs reprises recourir à l'équivalence en traduisant ces séquences figées comme en témoignent ces exemples :

"Lui, il ne comprend rien à rien!" نهه لا يعرف رأسه من رجليه". (MAHFOUZ,N.,p.62)

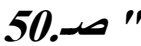

Le traducteur ne traduit pas littéralement (Il ne sait ni la tête ni les pieds). Le Français ne peut déchiffrer le sens de cette expression, car sa culture ne le possède pas. Il a pu résoudre cet obstacle par l'équivalence. Il en va de même cet exemple :

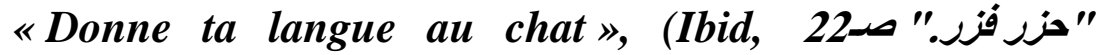
p.26.)

Dans les deux exemples précédents,le traducteur a utilisé l'adaptation pour donner le sens voulu. Autrement dit, il a choisi le terme " Lui, il ne comprend rien à rien!" et le terme " Donne ta langue au chat " qui convient la culture de la langue d'arrivée au lieu de la traduction littérale qui n'a pas de sens convenable.

En ce qui concerne l'expression imagée, la difficulté de la traduction réside dans l'impossibilité de trouver des structures syntaxiques et sémantiques des expressions idiomatiques analogues dans d'autres langues. Elles possèdent des propriétés syntaxiques et sémantiques particulières. Prenons comme exemple, cité dans le roman, (ركبه سابت صـ) qui est traduit par (Le pauvre, il est terrorisé)(MAHFOUZ,N, p.66). La traduction littérale des expressions idiomatiques modifie le sens et mène l'usager à un sens non plausible. Le traducteur qui emploie l'adaptation culturelle remplace le texte original par un parallèle culturel reconnu. Cette

60_ SVANE, Brynja, Culturèmes, références et les mots pour le dire - la traduction française de Jens Peter Jacobsen : 'Mogens' ,2006, p.138 In Eriksson, Olof (éd.). Översättning och kultur. Växjö, Växjö University Press, 2006 
Dr. Ibrahim Abd Elnabi ISSA

stratégie menace la crédibilité de la traduction parce qu'elle remplace des références liées à la culture de départ par d'autres références liées à la culture de la langue d'arrivée.

Le traducteur adopte aussi l'adaptation dans :

“La police, nul ne trouve grâce auprès d'elle .”

Saïd renchérit en murmurant:

"Pas même ceux qui font de l'excès de zèle."

البوليس لا بعجبه العجب.

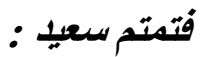

ولا الصيام في رجب.

(Ibid.,N.,p)

Le traducteur sait bien que le récepteur français ne comprendra pas le sens de cette expression idiomatique ( ولا الصيام في رجب) qui se traduit comme (Même, le jeûne au mois hégirien de Rajab). Celleci désigne que l'homme n'estime pas l'opinion de l'autre même si elle est correcte. Le traducteur adapte une phrase que les lecteurs de la langue cible peuvent comprendre. Considérons aussi cet exemple( 55 que le traducteur a traduit (Tu as un bon coeur. P.66 ). C'est un cas de l'adaptation. Le traducteur n'écrit pas (un cœur blanc), mais il utilise (un bon cœur) pour transmettre au lecteur le sens qu'il va comprendre.

Pour conclure ce point, nous remarquons comment le traducteur traite toutes les expressions idiomatiques au long du roman :

«Avec la franchise d'un soleil de juillet. "

صـ. 36 يصراحة شعس بيوليو ( Ibid.,p.44)

«Puisse la terre préserver celui qui la صد. 45 يا ارض أحفظي ما عليك foule!"

Sa famille une vraie tribu ( Ibid.,p.63)

Je vous en conjure ( Ibid.,p.65)

Je vous en supplie, Laissez-moi partir!

صد. 51.51أهله كالنمل

صد. 53 في عرضك كلك

صد. 52 في عرضك اتركني

( Ibid.,p.65)

Bois un coup (Ibid.,p. 66 (avale ta salive)

Tu as un bon coeur (Ibid.,p.66)

Il faut que tu prennes ton temps, que tu élabores un plan minutieux avant de fonder sur ta victime comme un oiseau de proie.
صد. 55 يلي ريقك

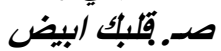

عليك ان تنتظر طويلا وتدبر أمرك

صد.بُم تنقض كالحدأة 
Traduction des référents culturels dans

le roman «le voleur et les chiens » vers le français

(MAHFOUZ,N.,p.)

La charité ne se fait pas prier. ( Ibid.,p.P.47)

Ce que je possède, je l'ai gagné ( Ibid.,p.41)

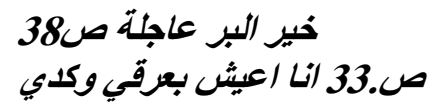

\section{8-15-Jeux de mots, culture et traduction}

Comment le traducteur traite-t-il le texte contenant un jeu verbal ? Avant de répondre à cette question, il nous parait indispensable de définir les jeux verbaux. Selon Landheer, le jeu de mots est " une expression linguistique contenant un élément ou plusieurs éléments de forme identique dont la bi- ou plurivalence sémantique a été exploitée consciemment par l'usager.» ${ }^{61}$ Pour certains linguistes, la définition de jeu de mots constitue un défi comme en témoigne Pierre Guiraud: "Le premier problème est la définition même du concept de jeu de mots et de ses limites, interférences et imbrications avec des faits voisins qui partagent avec lui tantôt leurs formes et tantôt leurs fonctions. ${ }^{62}$ Les jeux de mots ne dépendent pas seulement de codes linguistiques, mais aussi de systèmes culturels. Nous sommes contre l'avis selon lequel tous les jeux de mots sont intraduisibles, comme cet avis : "Par son intraduisibilité [...], le jeu de mots n'est pas simplement un caslimite de l'expérience traduisante. ${ }^{63}$ Mais nous pouvons prétendre que les jeux verbaux contiennent plusieurs types les uns sont traduisibles et les autres sont intraduisibles. Il y a des jeux de mots

61- LANDHEER, Roland, les règles du jeu de mots en français moderne, 1969,p.130. In A.G.Sciarone, A.J.Essen et A.A.Raad(rds.), Nomen.Leyden studies in Linguistics and Phonetics, 81-103. La Hague et Paris:Mouton.

62 - GUIRAUD, Pierre, Les jeux de mots, Que sais-je ? PUF, 1976,pp.5.6 63 - MAVRIKAKIS, Catherine, Compte rendu de There's a Double Tongue, TTR, vol. VII, no 2,1994, p. 210.in Geneviève Quillard, La traduction des jeux de mots dans les annonces publicitaires1, publicitaires1." TTR : traduction, terminologie, rédaction 141 (2001): 117-157. DOI : 10.7202/000531ar, p. 117
2018
العدد الرابع والعشرون (الجزء الثالث)
()
مجلة كلية التربية- جامعة عين شمس164 
Dr. Ibrahim Abd Elnabi ISSA

qui sont fondés sur la forme, sur le son et sur le sens. Parmi les types de jeu verbal : calembour, antanaclase, paronomase, ..etc. Il arrive que les traductions ne parviennent pas à rendre les effets humoristiques des textes sources. Le traducteur doit rendre compte de ces effets humoristiques et stylistiques. Considérons cet exemple du corpus :

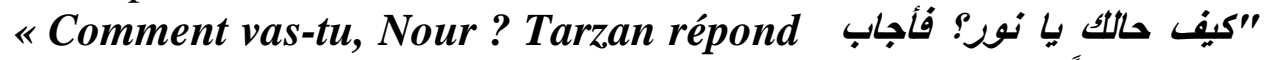
en souriant: "Comme tu vois, Nour la طرزان باسعاً: هي كما تري bien nommée rayonne de 50. نور ونور:" lumière ! »(Ibid.,N.,p.61)

Dans cet exemple, l'auteur du roman joue sur mot (Nour) qui est à la fois en arabe égyptien un nom propre et une lumière. Nous voyons que le traducteur n'ait pas réussi à préserver le jeu verbal et à le transmettre au lecteur étranger. Le récepteur ne sait pas que ce nom propre a une autre signification en arabe. Il ne rend pas compte de la valeur stylistique de cette phrase. C'est pourquoi le traducteur a ajouté en bas de la page une explication de ce jeu verbal : Jeu de mots, car (nour) signifie «lumière ». Selon Salah Mejri ${ }^{64}$, il y a les jeux de mots pragma-linguistiques qui proviennent du construit discursif et qui sont traduisibles parce qu'ils dépendent du contexte, et les jeux de mots linguistiques(sémantiques et formels) qui proviennent du pré-construit et qui sont intraduisibles. Nous concluons que certains types de jeux de mots ne sont pas traduisibles car ils comptent sur la culture de la langue de source.

\section{9-La traduction et la connotation}

La connotation est l'opposition de la dénotation. Le sens dénoté est le sens premier d'un mot, le sens objectif et le sens donné dans le dictionnaire. Le sens connoté est le sens second du mot. C'est le sens variable, subjectif et suggéré. Ce sens dépend de

64- MEJRI, S., "Traduire les jeux de mots: une approche linguistique", in Traduire au XXlème siècle. Tendances et perspectives, Université de Tessalonique, 2003. 
Traduction des référents culturels dans

le roman « le voleur et les chiens » vers le français

l'individu ou du contexte. Le traducteur doit avoir l'habileté de mettre en relief la différence entre la connotation et la dénotation. Dans le corpus, nous trouvons à plusieurs reprises que le traducteur des mots ou des phrases ayant un sens connoté. A titre d'exemple, cette phrase :

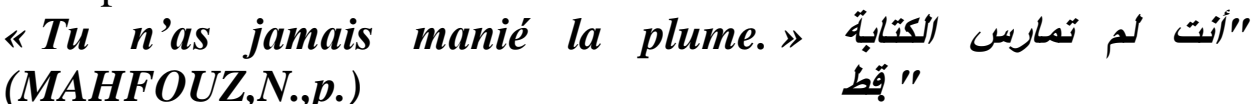
L'auteur ne veut pas dire que le protagoniste est un illettré. Mais, il n'est jamais journaliste. Il n'est pas compétent dans ce métier.

Dans notre corpus, les expressions de salutations sont aussi nombreuses. La manière par laquelle les Égyptiens se saluent n'est pas pareille à celle que les Français utilisent. Ces salutations peuvent contenir un sens connoté. Pour saluer Saïd Mahrane, on dit : (سعيل مهران !ألف نهار ابيض!) qui est traduit par (Quel jour béni!) (Ibid.,N.,p.10.) au lieu de (Mille journées blanches !) Le traducteur se rend compte que le lecteur étranger ne comprendrait pas cette expression qui est considérée comme connotation. Il en va de même dans l'expression (لبيلة بيضا بالصلاة علي النبي!). Le traducteur a employé l'équivalence (Quel jour faste et béni grâce au Prophète!) au lieu de (Quelle nuit blanche grâce au Prophète!) Passons maintenant à d'autres cas des phrases à sens connoté. Dans les phrases (تفرمل قدميها في البساط) et (نكسرصد14) le traducteur emploie la traduction littérale: (elle freine autant qu'elle peut en traînant des pieds) et (son coeur se brise.), (Ibid.,p.17.)

\section{0-Critique de la traduction}

Nous avons déjà signalé que le traducteur doit être à la fois biculturel et bilingue. Il ne doit pas négliger certains aspects culturels qui sont présents dans le texte-source. Il prend en considération les mots qui ont une allusion culturelle. Nous remarquons que le traducteur n'a pas utilisé, à plusieurs reprises, la bonne équivalence de certaines expressions. Dans ce cas, nous pourrions dire qu'il néglige la culture de la L2 comme en témoigne 
Dr. Ibrahim Abd Elnabi ISSA

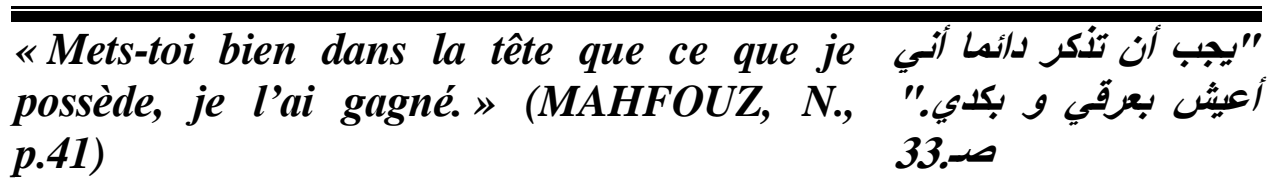

Le traducteur ne fait pas attention à l'expression suivante: « Gagner son pain à la sueur de son front » qui fait référence à la Bible. En effet, dans la Genèse (chapitre 3, verset 19.) 65 "Gagner son pain à la sueur de son front" signifie que l'on gagne de quoi se nourrir soi-même, et ce, par le biais du travail. Ainsi, dans l'expression suivante, il n'emploie pas l'équivalent convenable :

«Il place Son mystère dans les plus infimes de Ses créatures. »(Ibid.,p.25)

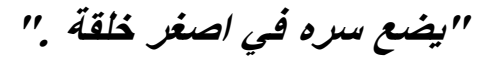
21

Selon nous, il fallait utiliser le proverbe suivant : « les petits ruisseaux font les grandes rivières. » Revenons à cet exemple :

«Saïd appuie sur la détente et le coup éclate comme le hurlement d'un démon dans la nuit. »(Ibid.,p.72)

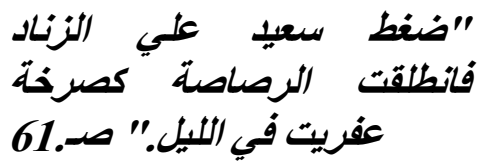

Le traducteur ne respecte pas le sens du texte intégral. Il remplace le mot (عفريت) qui signifie (dijn) par le mot (démon). Ainsi (الصبار) il utilise le mot (le figuier) au lieu de (cactacées). Le figuier signifie en arabe (التين).

Le traducteur utilise l'adaptation dans les cas de( هرب منزيرة) (خنزيرة/الحمام). Le mot (خنزيرة) se traduit par (truie). Pour nous, le traducteur a commis une erreur en utilisant la traduction (salope) (Ibid.,p89.), parce que le mot (truie), elle-même, désigne ,par extension, l'injure (femme malpropre ou femme de mauvaise réputation). Ainsi le traducteur utilise-t-il (une nuée d'oiseaux),(Ibid,93), au lieu de (une nuée de pigeons).

Pour citer un toponyme, le traducteur doit recourir à l'emprunt. Mais dans notre corpus, il ne suit pas de procédé déterminé. Il

65 - http://www.linternaute.com/expression/langue-

francaise/289/gagner-son-pain-a-la-sueur-de-son-front/

2018 العدد الرابع والعشرون (الجزء الثالث)

()

مجلة كلية التربية- جامعة عين شمس 167 
Traduction des référents culturels dans

le roman « le voleur et les chiens » vers le français

utilise à la fois l'emprunt et la traduction littérale comme en témoignent ces deux exemples :

"Il a laissé la voiture à l'autre bout de la rue, du côté de la place de la

Citadelle $»($ Ibid.,p.71)

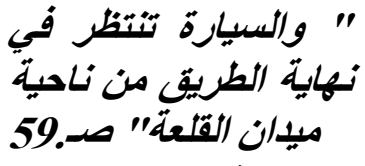

"Il appuie sur l'accélérateur et bientôt aborde le quartier de Manchiyyet el-Bakri. »( MAHFOUZ,N.,p.74)

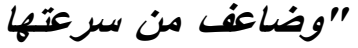

Dans le premier exemple, le traducteur recourt à la traduction littérale, il fallait utiliser l'emprunt. Dans d'autres exemples, le traducteur préfère l'adaptation comme dans les cas : (بلع ريقك () Il préfère utilise (bois un coup) du (Avale ta salive). Il préfère aussi la transposition et l'adaptation dans (وابعد عن حبل المشنقة) . Il utilise «Moins exposé à l'échafaud." (Ibid.,p. 47). La corde de pendaison est remplacée par (échafaud). Il emploie (moins exposé $=$ adverbe+participe passé au lieu de sujet+verbe + préposition je m’éloigne de .»

Dans cet exemple, 《و وهو علي الخاذوق.صد. qui est traduit par «Empalé sur un pieu. » (Ibid.,p.25). C'est une traduction littérale, mais le traducteur ne prend pas en considération le sens figuré qui signifie ici : il est perplexe.

Pour conclure ce point, nous remarquons que la traduction culturelle a besoin de procédés et de stratégies par lesquels le traducteur peut soigneusement transférer le contenu culturel. Dans ce cas, la traduction littérale ne peut résoudre ce problème.

\section{1-Conclusion}

Notre travail avait pour but d'examiner comment les référents culturels qui sont présents dans l'œuvre "le voleur et les chiens» se voient dans la traduction de ce roman. Nous avons décidé de cerner cette question en mettant l'accent sur divers éléments de cette œuvre: les noms propres, les toponymes, les expressions idiomatiques, les proverbes,etc. Le traducteur doit chercher à 
conserver le cadre socioculturel et historique de la langue source. Malgré les divergences culturelles entre les deux langues, le traducteur doit modifier les énoncés en fonction des règles et de la culture de la langue 2 pour éviter les malentendus.

À travers cette étude, il ressort que toutes les langues ont à la fois des divergences linguistiques et culturelles. Finalement, nous souhaitons que d'autres chercheurs contribuent de leur part à la dissipation de la notion d'intraduisibilité de la culture d'autres langues. 
Traduction des référents culturels dans

le roman « le voleur et les chiens » vers le français

\section{BIBLIOGRAPHIE}

\section{I-CORPUS}

\section{Corpus francais}

MAHFOUZ, Naguib, «le voleur et les chiens », traduit de l'arabe par Khaled Osman, 1961, pour la traduction française, Babel Sindbad, 1996.

Corpus arabe

-محفوظ ، نجيب، اللص والكلاب ، مكتبة مصر، 1998

\section{II- THÉORIQUES DE TRADUCTION}

-BALLARD, M.,La traduction de l' anglais au français, Paris, Ed.Nathan, 1998

"Le cultèreme en traduction : entre sens indice et écriture ». In : Eriksson O. (éd). Översättning och kultur, föredrag från ett symposium vid Växjö universitet 17-18 november 2006. Växjö : Växjö University Press, pp 19-40.2007, p.22. In : Sara Lindsten, Comment traduire la culture ? Etude sur la traduction des mots culturels dans la traduction d'un roman de Mons Kallentoft, Göteborgs universitet,2013 ,Le nom propre en traduction, Paris, Ophrys, 2001

-BERMAN, Antoine, L'épreuve de l'étranger, culture et traduction dans l'Allemagne romantique, Paris, collection les Essais $\left(\mathrm{n}^{\circ} 226\right)$, Gallimard,1984 , «Au début était le traducteur », TTR : traduction, terminologie, rédaction, 14.2, 2001 p. 17.in MEHNERT Sabine « «Traduire, c'est trahir»? Pour une mise en question des notions de vérité, de fidélité et d'identité à partir de la traduction », Trajectoires [En ligne], 9|2015, mis en ligne le 15 décembre 2015, consulté le 08 novembre 2017. URL: http://trajectoires.revues.org/1649

-BURGER, H., Phraseology: An international handbook of contemporary research, Germany: Braunschweig, 2007

-CORDONNIER, J.L, Traduction et culture, Paris, Hatier, 1995

-ECO, Umberto, Dire presque la même chose, Expériences de traduction, Paris, Grasset, 2007

-FICHOU, J-P., Enseigner les civilisations, Paris, PUF, 1979 In Real, E., Jiménez, D., Pujante, D. y Cortijo, A. (eds.), Écrire, traduire et 
Dr. Ibrahim Abd Elnabi ISSA

représenter la fête, Universitat de València, 2001, pp. 723-733, I.S.B.N.: 84-370-5141-X.

-GRASS, Thierry "La traduction comme appropriation : le cas des toponymes étrangers." Meta 514, 2006

- GUIRAUD, Pierre, Les jeux de mots, Que sais-je ? PUF, 1976

-KLEIBER, G., Problèmes de référence : descriptions définies et noms propres, Paris, Klincksieck, 1981

-LADMIRAL, Jean René, Traduire, Théorèmes pour la traduction, coll.«.Tel», Paris, Gallimard, 1994, p.18

- LANDHEER, Roland, les règles du jeu de mots en français moderne, 1969 In A.G.Sciarone, A.J.Essen et A.A.Raad(rds.), Nomen.Leyden studies in Linguistics and Phonetics, 81-103. La Hague et Paris:Mouton.

-LEDERER, Marianne, La traduction aujourd'hui, Paris: Hachette, 1994, p.123 In: Camilla Skilbred, Le transfert du culturel dans la traduction de Poisson d'or de Le Clézio, Université d'Oslo, 2005

-MAVRIKAKIS, Catherine, Compte rendu de There's a Double Tongue, TTR, vol. VII, no 2,1994, p. 210.

-MEJRI, S., "Traduire les jeux de mots: une approche linguistique", in Traduire au XXIème siècle. Tendances et perspectives, Université de Tessalonique, 2003

-MOUNIN, Georges, les problèmes théoriques de la traduction, Paris, Gallimard, 1963

-

Mardaga, 1976.

,Linguistique et traduction, Belguim, Dessart \&

-MOUSSAOUI ,Yamina Leila, l'influence culturelle sur la traduction de la poésie populaire : Traduire une langue ou un dialecte ? Université Tlemcen No.23, 2014.

-NORD, Christiane, La traduction, une activité ciblée, Introduction aux approches fonctionnalistes, Artois Presses Université, 2008.

-PALICZKA, Anna, Nom propre et ses dérivés en traduction, Université de Silésie,2009, p.5.

-PERGNIER, M., Les fondements sociolinguistiques de la traduction, Presses Universitaires de Lille, 1978.

-QUILLARD, Geneviève, La traduction des jeux de mots dans les annonces publicitaires1, publicitaires1." TTR : traduction, terminologie, rédaction 141,2001 
Traduction des référents culturels dans

le roman « le voleur et les chiens » vers le français

- RAKOVÁ, Zuzana. La traduction équivalente, adéquate ou fonctionnelle-quelle doctrine traductologique pour le XXIe siècle?. Études romanes de Brno, 2013.

-SELESKOVITCH, Danica et LEDERER, Marianne; Interpréter pour traduire, Paris, Didier érudition, 1984

- SORIANO, Ascensión Sierra, Les fêtes au fil des mois : problèmes de traduction, Universitat de València, 2001

-SVANE, B., «Comment traduire la réalité ? Étude de la traduction des expressions référentielles», 1998, p.93. In : Eriksson, O. (éd). Språk- och kulturkontraster, om översättning till och från franska. Åbo : Åbo Akademis förlag, pp. 93-118,

-SVANE, Brynja, Culturèmes, références et les mots pour le dire - la traduction française de Jens Peter Jacobsen : 'Mogens', 2007. In : Eriksson, Olof (éd.). Översättning och kultur, föredrag från ett symposium vid, Växjö University Press, 2006, pp. 131-147.

-TATILON, Claude et REISS Katharina, La critique des traductions, ses possibilités et ses limites, traduit de l'allemand par Catherine Bocquet, Cahier de l'Université d'Artois, 32/2002, Arras, Artois Presses Université, 2002

-TEGELBERG, E., « Kvällstidning », journal à sensation? Le problème de la traduction en français des «mots culturels » suédois », Moderna språk. no 2,2004

-VINAY, J.-P. et DARBELNET, J., Stylistique comparée du français et de l'anglais, Paris, Didier, 1967

\section{III-ARTICLES DE PÉRIODIQUES}

-CUCIUC, Nina, Traduction culturelle: Transfert de culturèmes, Presses Universitaires de France, «La linguistique », Vol. 47, 2011/2

-DANLOS, Laurence., "La morphosyntaxe des expressions figées ", Langages, 63, 1981

Larousse, 1988

L., Les expressions figées, Langages $n^{\circ} 90$, Paris,

- FUENTES, Sandrine. LA TRADUCTION DES NOMS DE PROFESSION DANS UN SYSTÈME DE DICTIONNAIRES ÉLECTRONIQUES COORDONNÉS (ES-FR), Verbum,2016. 


\section{Dr. Ibrahim Abd Elnabi ISSA}

-LECUIT Emeline et al., "La traduction des noms propres : une étude en corpus ", Corpus [En ligne], 10 | 2011, mis en ligne le 18 juin 2012, consulté le 30 Mars 2018.

-LONTI, Bela, Le phénomène des parémies et le problème de leur traduction ou Comment «dire» une culture dans une langue étrangère, Université d'État Ilia, Tbilissi, Géorgie, 2014,pp159-170.

-MERGER, M.-F., Les onomatopées et les interjections dans la bande dessinée Titeuf et leurs traductions en italien,2012, p. 25

-J. Podeur (dir.), Tradurre il fumetto/ Traduire la bande dessinée (pp. 1328).

-RICHET, Bertrand, Quelques données et réflexions sur la traduction des interjections, Traductologie. Michel Ballard (éd.). Oralité et traduction, Arras: Artois Presses Université, pp.79-128, 2001. , B., Quelques données et réflexions sur la traduction des interjections, 2001 p.89

-SÉVRY, Jean, Une fidélité impossible: traduire une auvre africaine anglophone. Palimpsestes. Revue de traduction, 1998, 11: p.134 in Petronela Munteanu, Traduction et culture,université de suceava,2011 -TALLARICO, Giovanni. Stratégies culturelles dans la traduction des livres pour enfants: le cas de Geronimo Stilton. Parallèles, 2015

- VAGUER, Céline, Expressions figées et traduction : langue, culture, traduction automatique, apprentissage, lexique , 2014. Disponible sur le site : https://hal.archives-ouvertes.fr/hal-00980140

\section{IV-DICTIONNAIRES}

-DUBOIS ,Jean et al., Dictionnaire de linguistique, Larousse, Paris, 2002, p. 486

Thèses

\section{V- THÈSES CONSULTÉES}

-SKILBRED, Camilla, Le transfert du culturel dans la traduction de" Poisson d'or" de Le Clézio. 2005. Master's Thesis.

\section{VI-SITES D'INTERNET}

-http://www.zurnalai.vu.lt / verbum/ article/ view/10287/8159(Consulté le 15-03-2018) 
Traduction des référents culturels dans

le roman «le voleur et les chiens » vers le français

-http://www.toutpourlebac.com/dossiers / 120/ bac-fiche-anglais--lesprocedes-de-traduction/ 341/la-transposition.html (Consulté le 10-5-2018) -http://revue.ummto. dz/index.php/pla/ article /view/ 10 (Consulté le 103-2018)

-http://translationjournal. net/journal/ 18fidelite . htm (Consulté le 1-022018)

-http://mugtama.com/translations/item/25632-2015-11-12-05-18-11.html.

(Consulté: le 25-6-2016)

http://www.lefigaro.fr/international/2015/11/09/01003-20151109

ARTFIG 00236-bouteflika-gouverne-t-il-encore-l-algerie.php (Consulté le 16-8-2016)

في-استفتاء-لجريدة_ليكيب_الفرنسية-2010/28

2015-فرنسا_الاكثر -جاهزية_لاستضافة_Consulté : le 28-6-2016)

-https://fr.wikipedia.org/wiki/Fête_des_Mères (consulté le 18-04-2018)

-https://fr.wikipedia.org/wiki/Ka'ak (Consulté le 20-04-2018.)

-http://cladelcroix.mondoblog.org/us-coutumes-nouvel-an-francais/

(consulté le 20-04-2018)

-http://ojs.iliauni.edu.ge/index.php/eish/article/view/64/50

- $\quad$ http://www.linternaute.com/expression/langue-francaise/289/gagner-

son-pain-a-la-sueur-de-son-front/ (consulté le 20-04-2018)

العدد الرابع والعشرون (الجزء الثالث) 2018

()

مجلة كلية التربية- جامعة عين شمس174 